\title{
SUSTAINABLE ENVIRONMENTAL DESIGN OF HEALTHCARE BUILDINGS
}

\author{
Ahmed Al Hussein Tohlob \\ Architectural Dept, Misr Institute for Engineering and Technology, Mansoura, Egypt \\ E-mail: Eng_ahmedtohlob@hotmail.com
}

\begin{abstract}
Buildings of healthcare should have requirements and needs of the architectural design. These requirements stem from the actual needs of each society, but at the same time can benefit effectively from the experiences of developed countries in this area - both were similar circumstances or different in order to reach the highest performance of the building. In this case, the requirements of indicators are used as a checklist to determine which different elements to be met and relied on throughout the studies carried out by some international organizations, research and reports of interest. Such checklists can be considered as efficient source to determine the requirements to be accessible. In the same context, there are several determinants of help to improve the environmental performance of the building and checklist adapted to the building with the surrounding environment without damaging the building or the environment with the convenience of individuals, which may result in knowledge of the requirements of the design and an analysis of each side to develop on a regular, ongoing basis. Hence, the research will deal with findings of the performance of a number of global systems associated with sustainable healthcare buildings and also the evaluation system in Egypt as the local system. It aims to clarify each system and credit of the achievement of those parameters in order to access to the determinants of improving the performance of the building in the context of a specific and comprehensive environmental analysis. It will gain access to the methodology in the context of the most important determinants affecting the performance of the building in terms of energy, water, emissions, transport, materials and resources.
\end{abstract}

\section{KEY WORDS: Health Care Buildings, Sustainable Design Strategies, Green Architecture, Sustainable Design,}

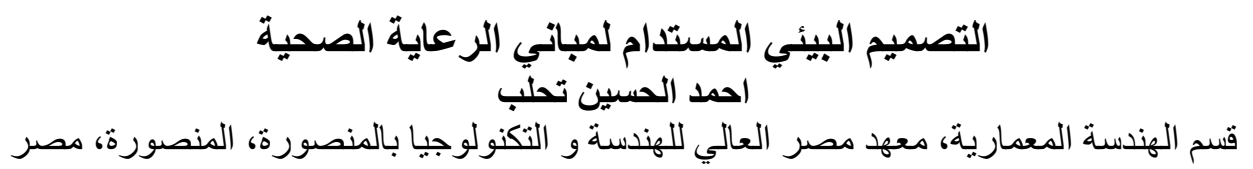

البريد الاليكتروني:E-mail: Eng_ahmedtohlob@hotmail.com

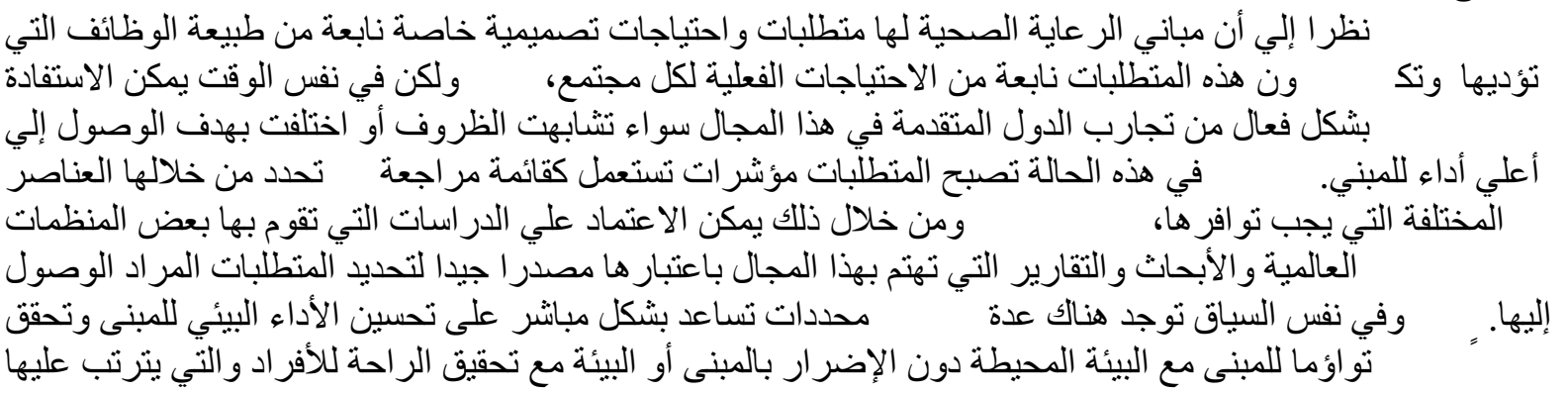




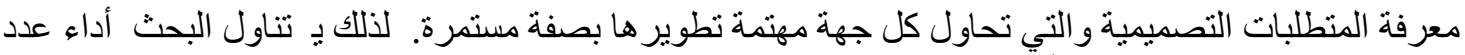

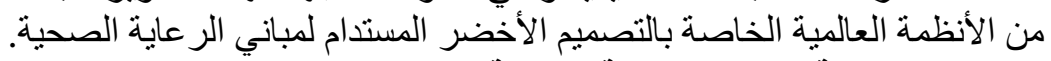

الكلمات المفتاحية : مباني الرعاية الصحية ، استراتيجيات التصميم المستدام ، العمارة الخضراءة، التصائة التصيم المستدام.

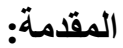

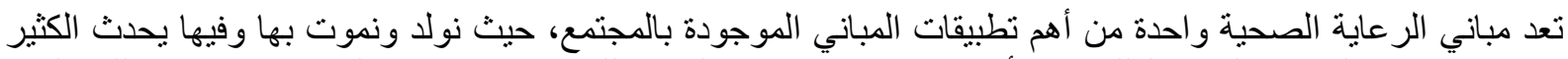

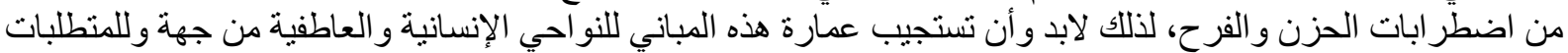

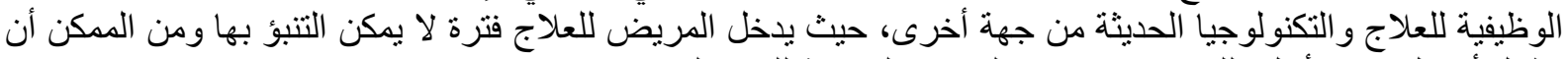

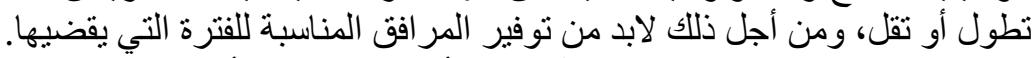

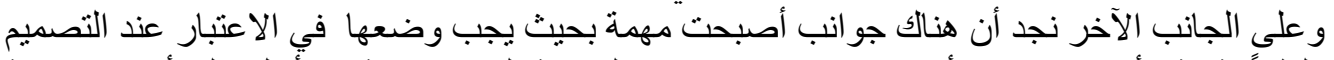

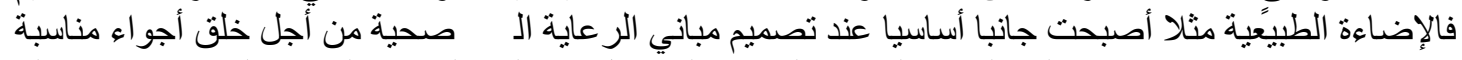

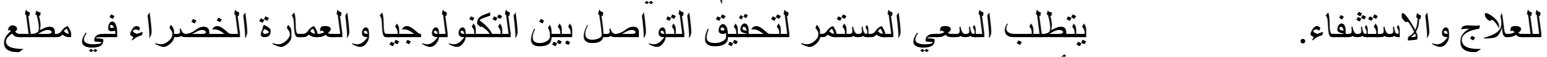

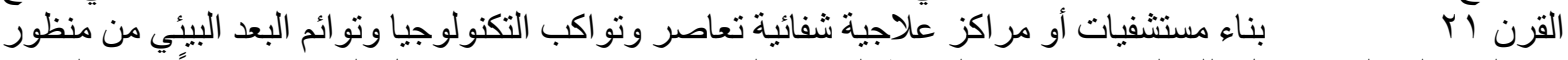

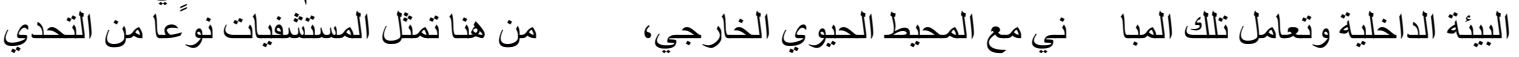

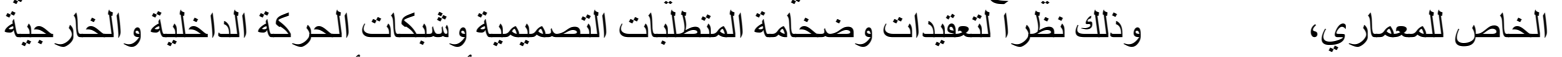

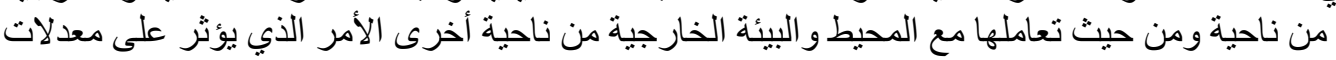

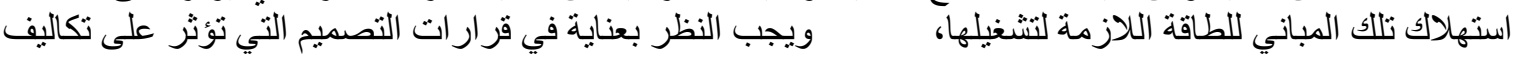

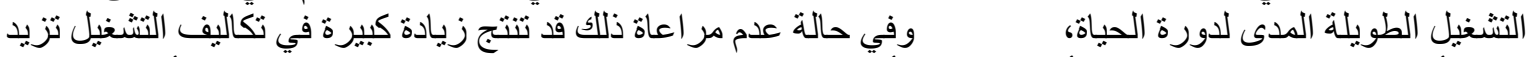

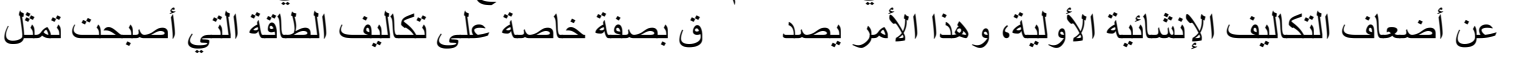

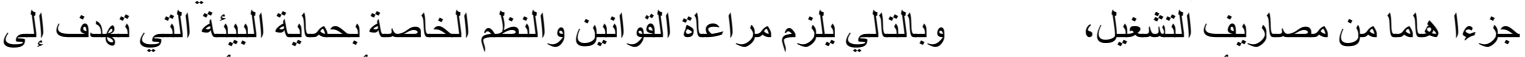

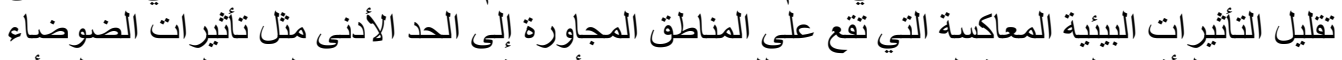

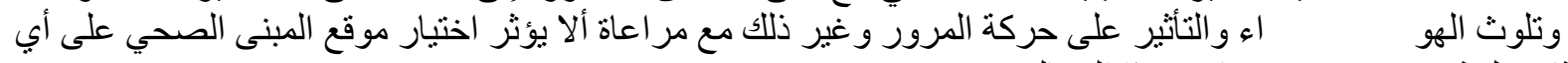
آثار سلبية غير مر غوب فيها في هذا المجال.

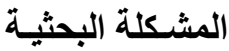

إن عملية التصميم لمباني الر عاية الصحية في كثير من الأحيان نجدها مترتبة على الاحتياجات الوظيفية للعلوم الطبية

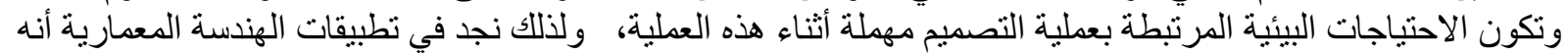

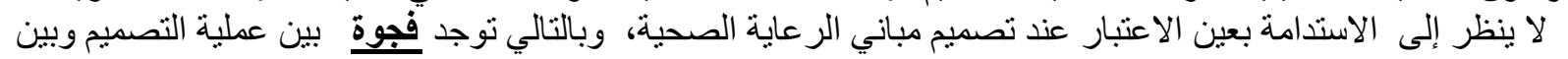

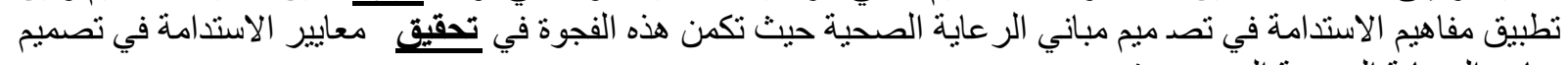

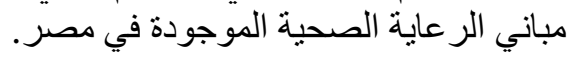

يهذف البحث إلي تطوير معايير التصميم المستدام لتصميم مباني الرعاية الصحية من أجل تعزيز دمج المبادئ البيئية

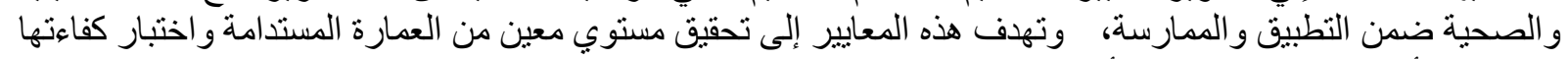

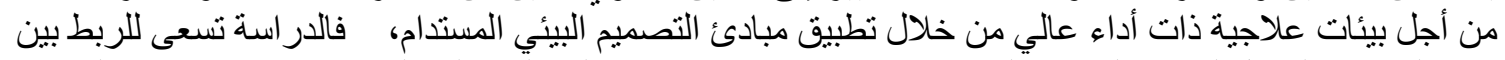

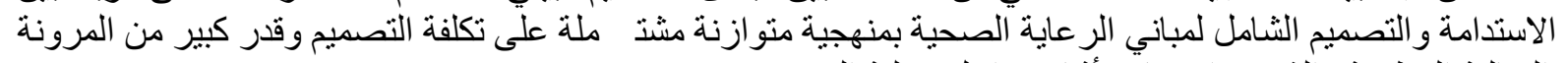

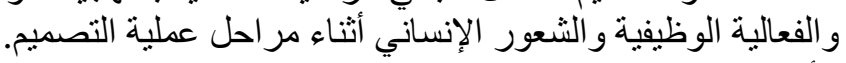

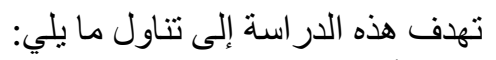

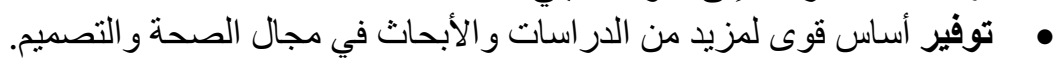

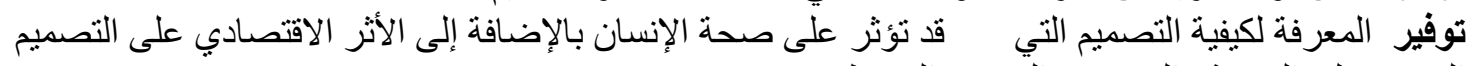

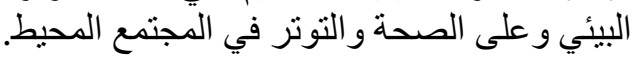

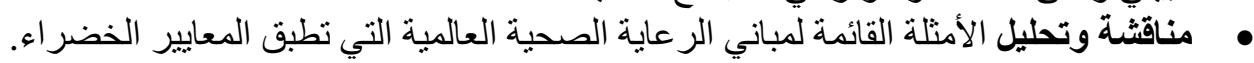

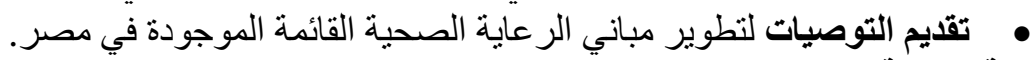

الفرضية البحثية...

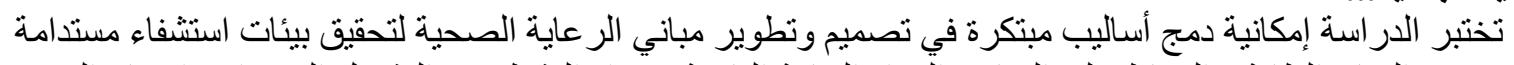

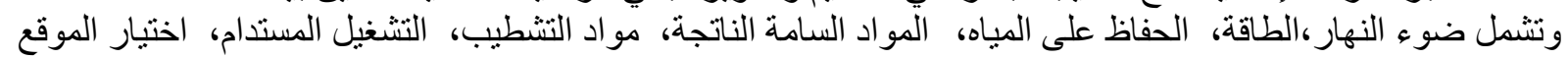
وكفاءة البيئة المحيطة حسب البنار الطنة التيجيات التصميم المستدام.

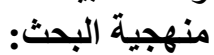

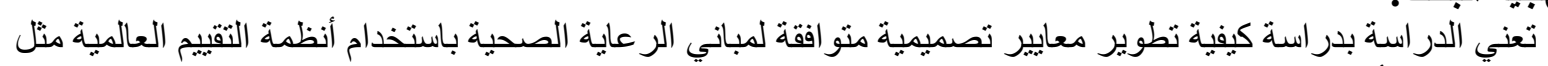

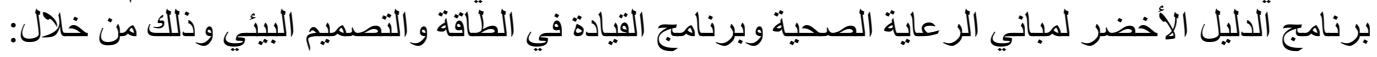

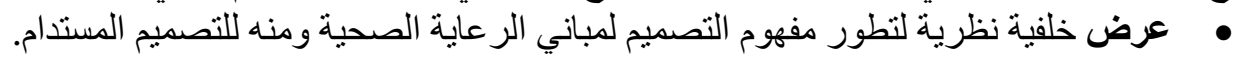


مناقشة وتحليل أنظمة تقييم مباني الرعاية الصحية العالمية و المحلية.

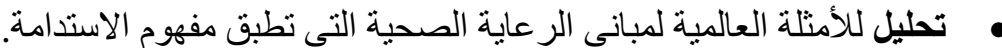

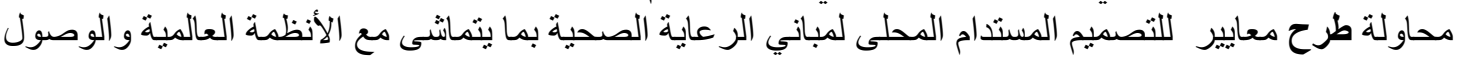

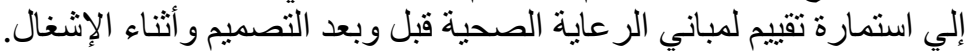

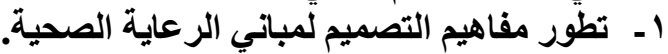

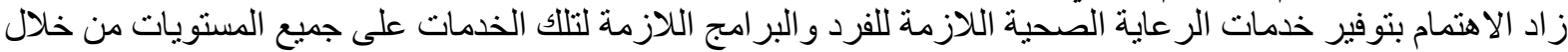

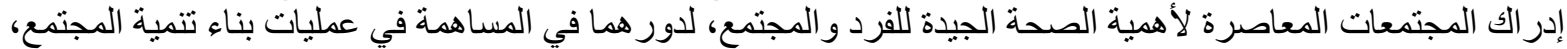

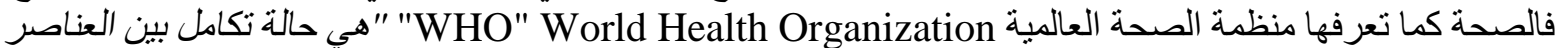

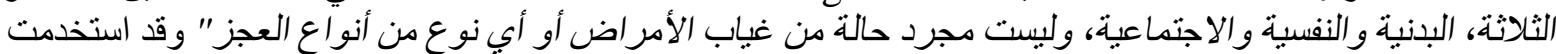

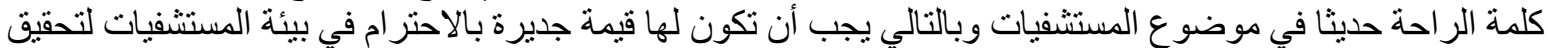

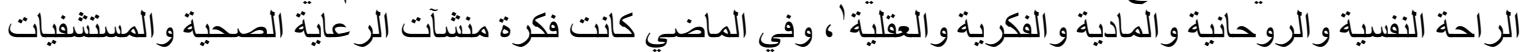

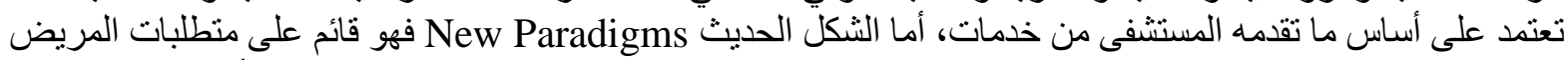

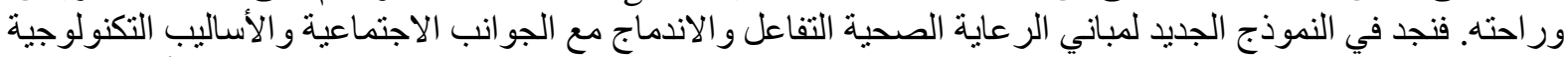

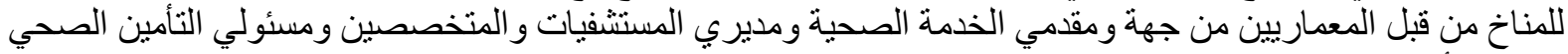

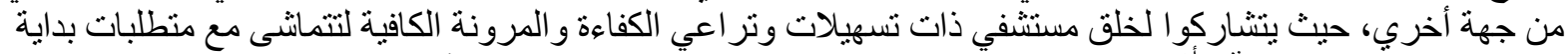

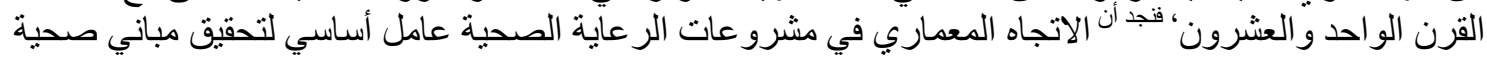

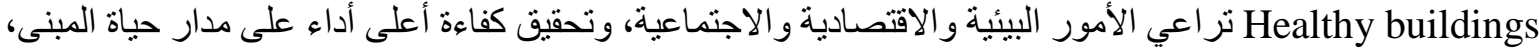

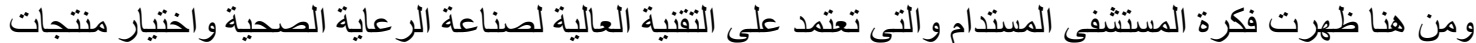

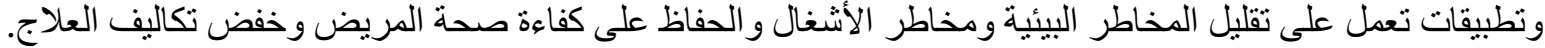

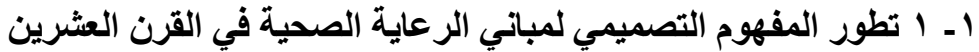

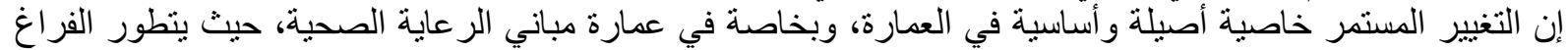

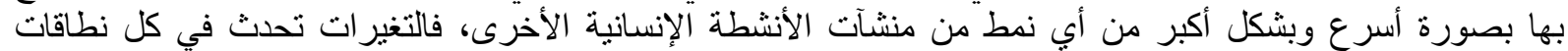

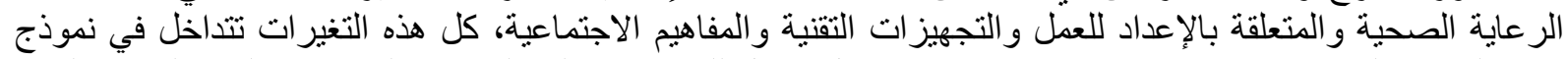

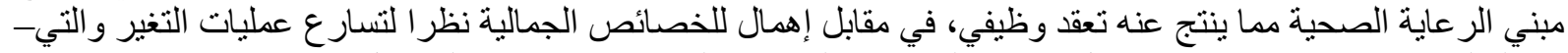

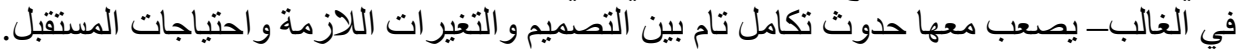

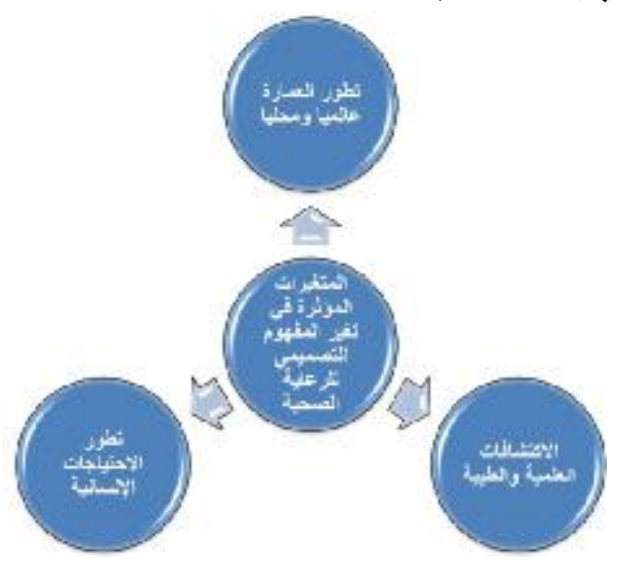

شكل ( 1) المتغيرات الثلاثة المؤثرة في تغير المفهوم التصميمي لمباني الرعاية الصحية(المصدر: الباحث).

شكل ( r) مراحل تطور العمارة منذ منتصف القرن 19 وحني مطلع القرن آب (المصدر: الباحث).

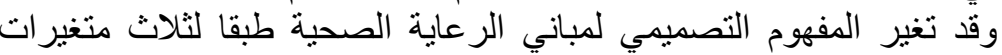
أساسية وهي كالتالي:

أولا: تغير وتطور كالتيا: العمارة عالميا ومحليا.

ثانيا: تغير وتطور متطلبات مباني الروعاية الصحية لتحقيق الرعاية

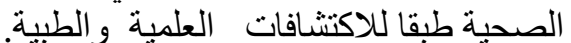

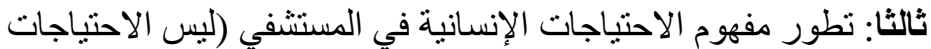

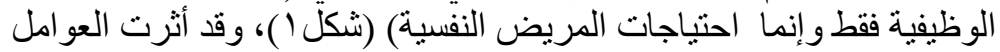
الثلاثة السابقة علي المفهوم التصميمي لمباني الر عاية الصحية في في القرن العشرين، ويتضح ذلك من خلابله

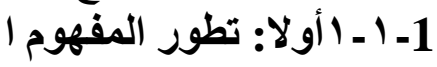

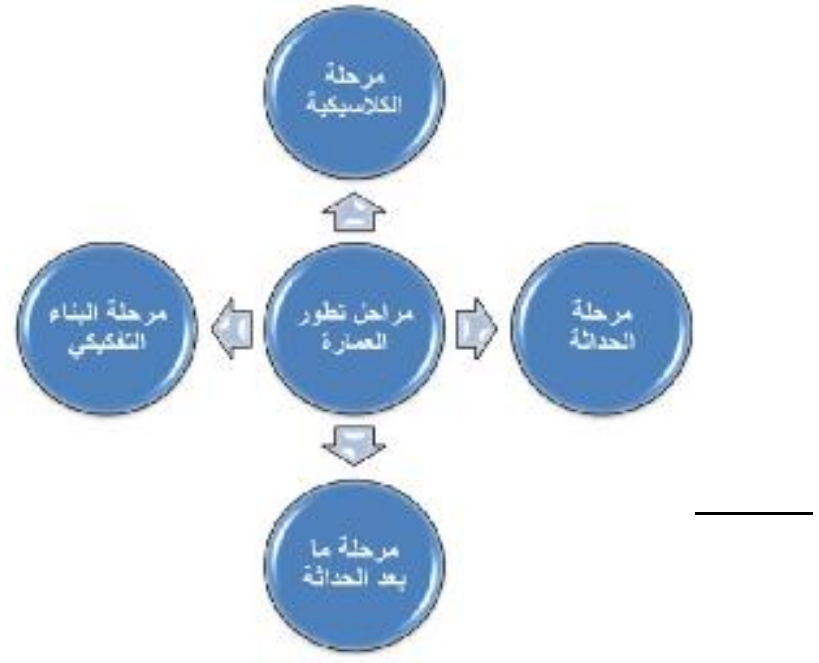


لتصميمي لمباني الرعاية الصحية طبقا لتطور العمارة

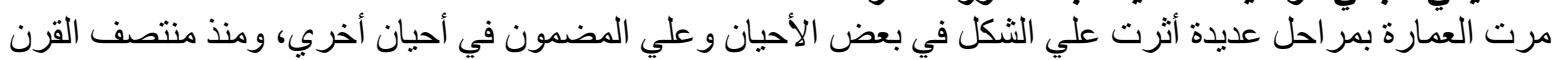

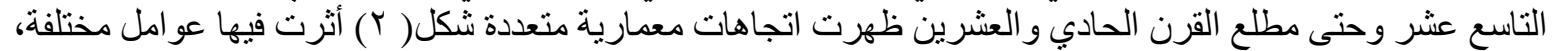

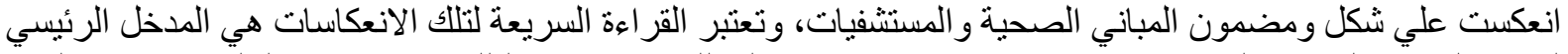

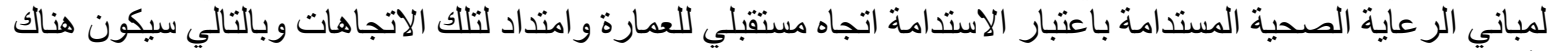

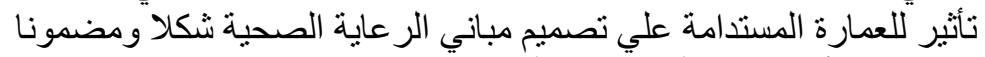

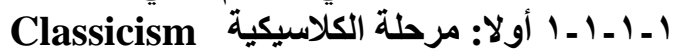

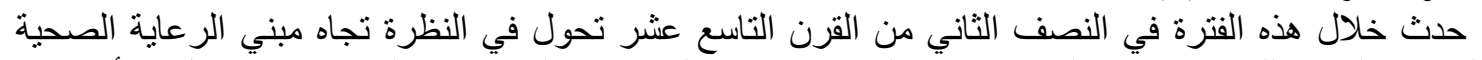

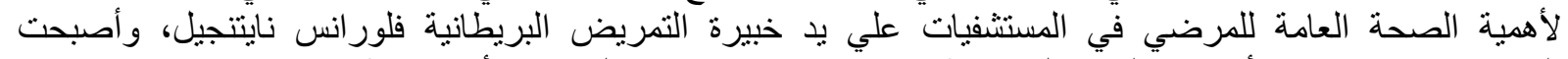

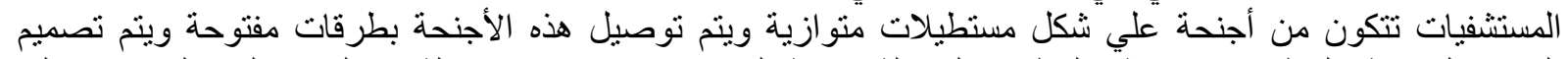

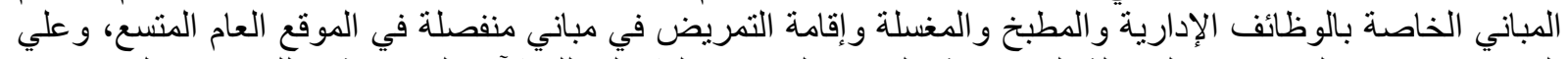

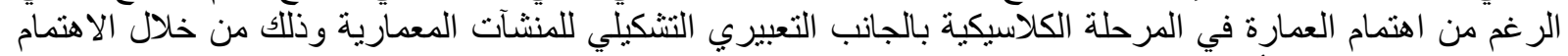

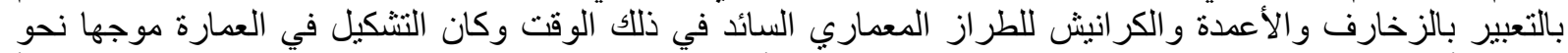

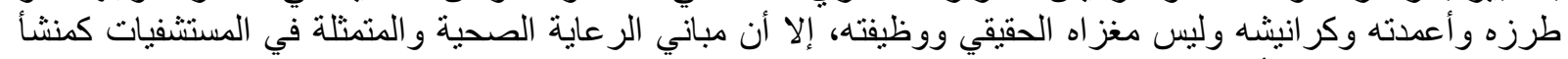

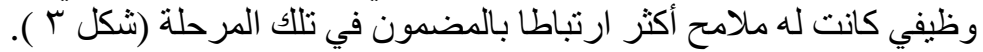
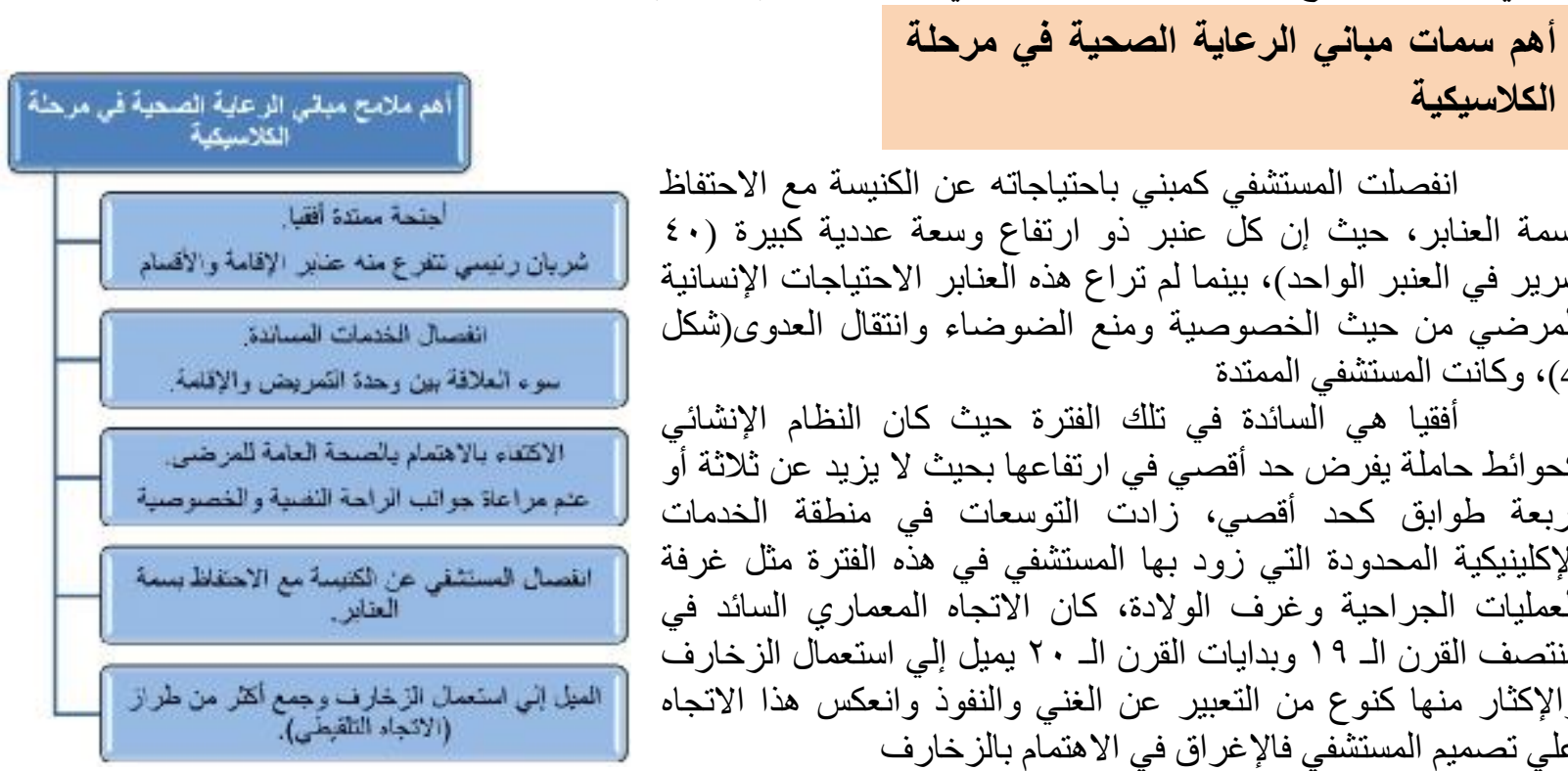

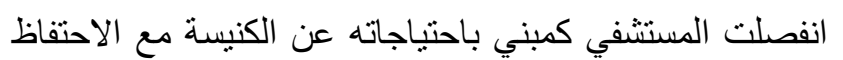

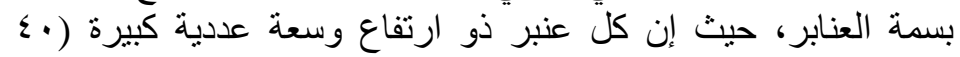

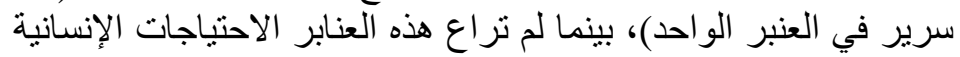

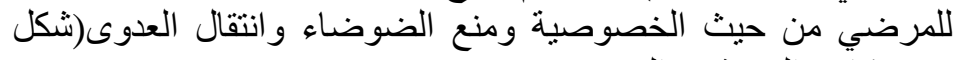
4)، وكانت المستشفي الممتدة

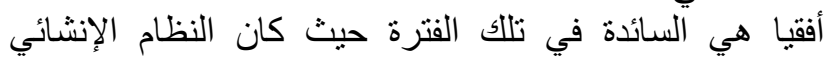

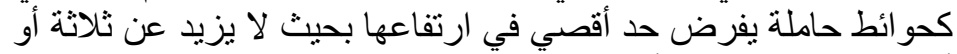

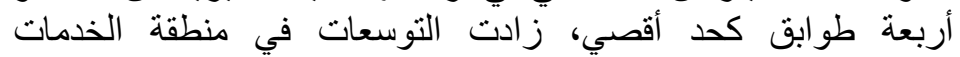

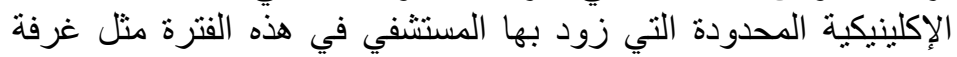

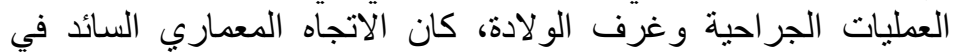

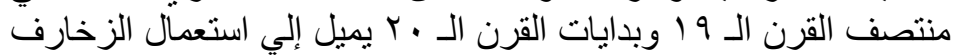

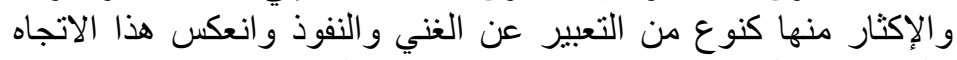

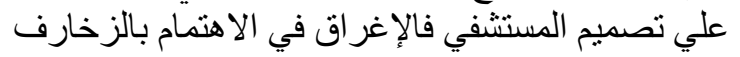

شكل ( "آ) أهم سمات مباني الرعاية الصحية في مرحلة الكلاسيكية

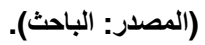

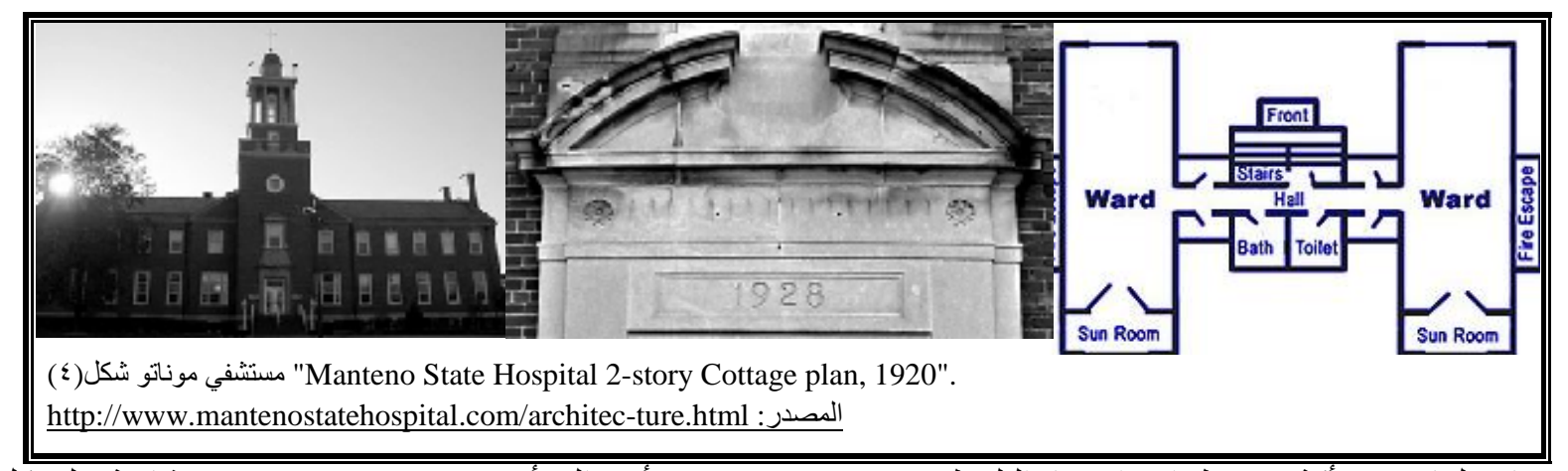

وتفاصيلها وجمع أكثر من طر از (الاتجاه التلقيطي) Eclecticism أدي إلي أن تضفي ملامح موحدة ومتشابهة علي كل

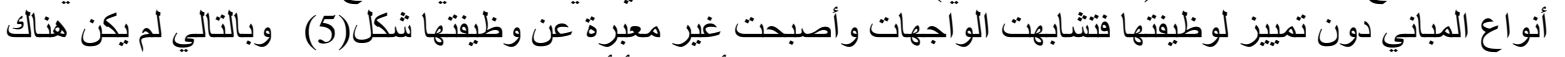

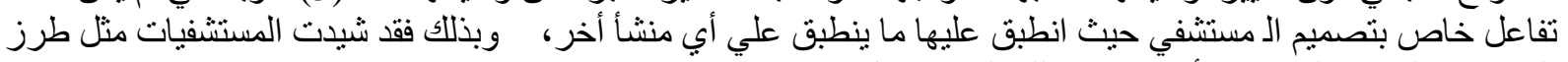
القصور و المباني العامة في أوروبا في ذلك الوقت شكل علئ (6). 


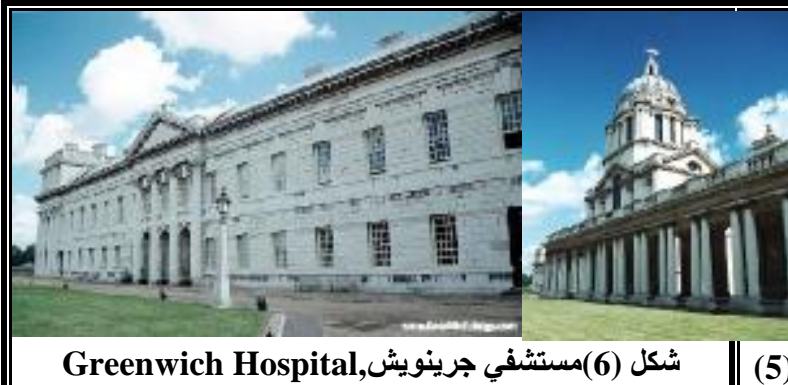

England, 1696 to 1715.

http://www.sandiegohistory.org/journal

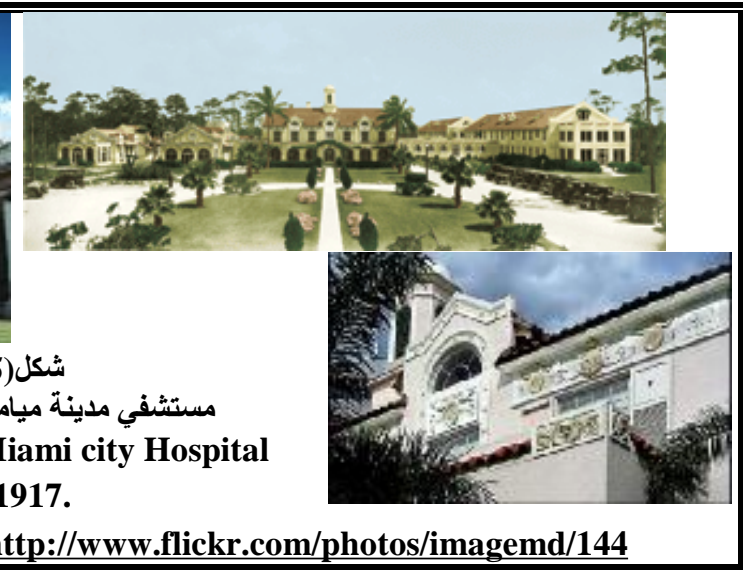

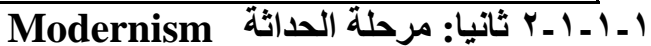

لم يمس التيار الفكري في هذه المرحلة النواحي العيات العقائدية ولم يثر

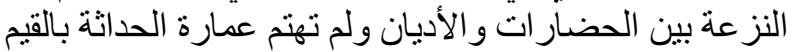

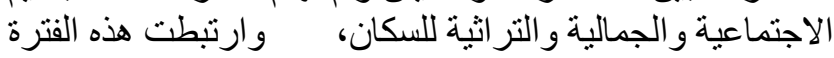

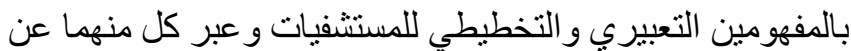

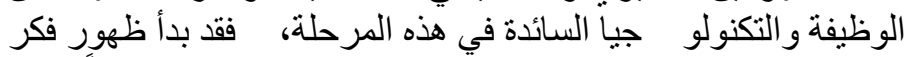

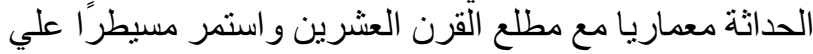

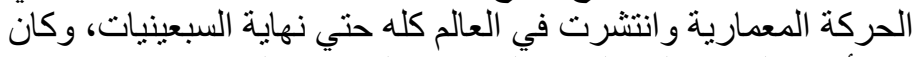

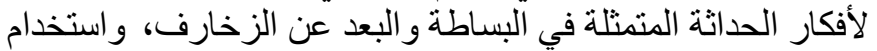

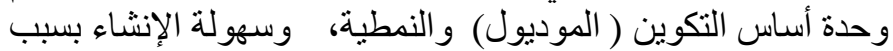

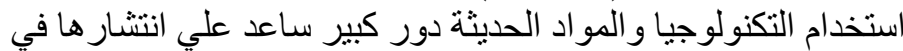

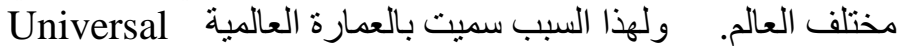
Architecture

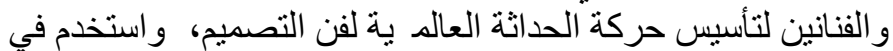

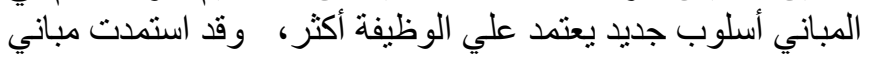

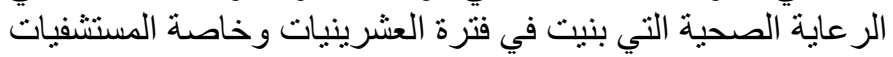

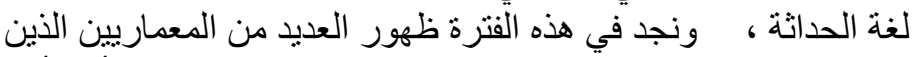
غفلوا عن فكر الحداثة في تصميم المستشفيات مذّ ل المعماري ألفر ألتو النو

الذي صمم مصحة تيوبر كيولسيس Tuberculosis Sanatorium

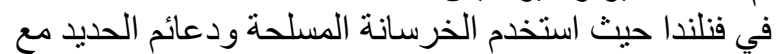

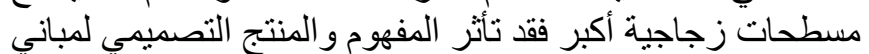

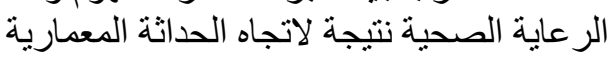

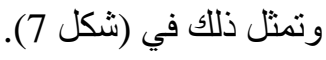

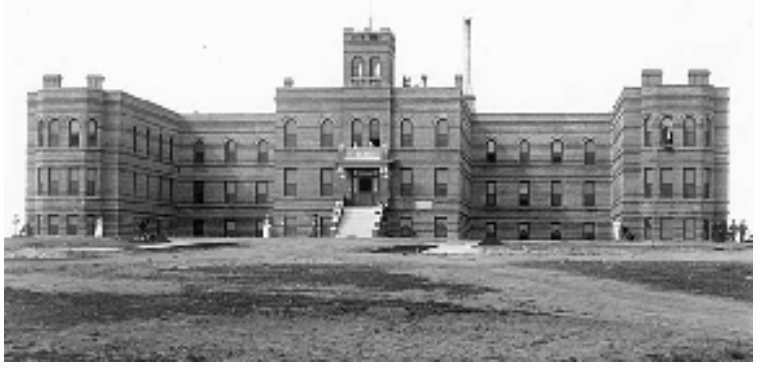




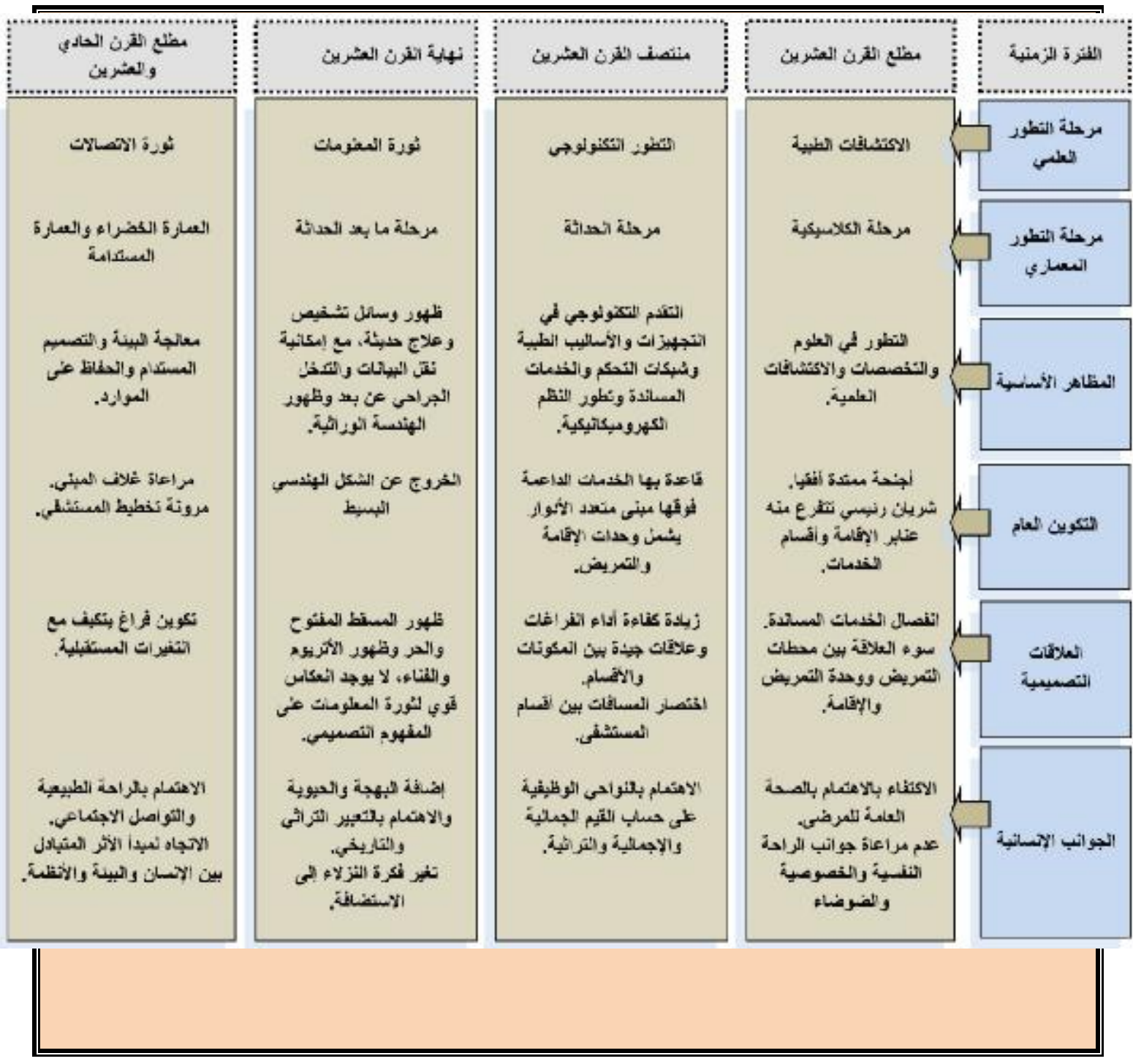

ومن خلال العرض السابق يوضح جدول 1 التطور الحادث لمباني الرعاية الصحية المتمثلة في المستشفيات من نهاية القرن التاسع عشر إلى مطلع القرن الحادي و العشرين.

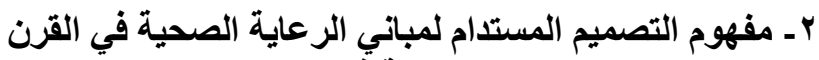

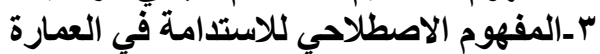

إن مصطلح العمارة المستدامة يركز على الاستدامة في العمارة، ولكل منهما فرع من المعرفة يخرج نظام وقو اعد تحمل

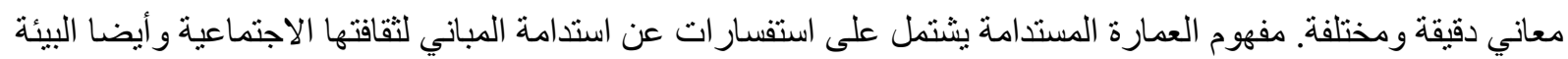

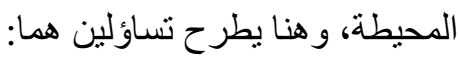

الأول: ماذا تعنى الاستدامة للعمارة:

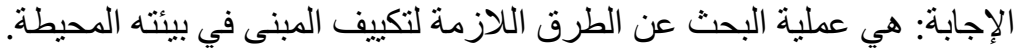

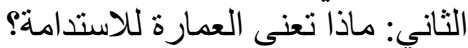
الإجابة: هي تحقيق عمارة تعمل كوسيط يساهم في اكتساب معنى الحياة البشرية في مليون مجهول.

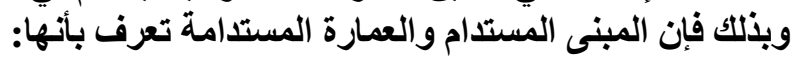

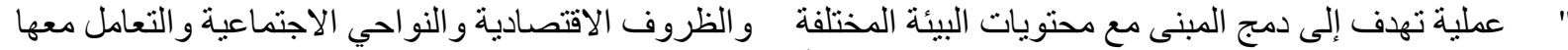

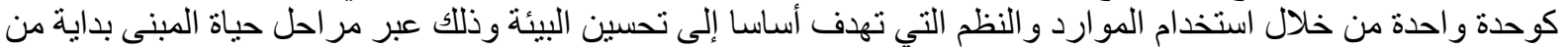

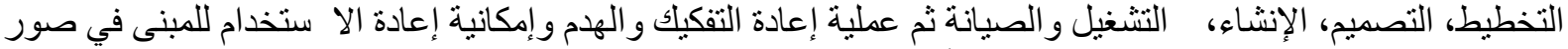
مختلفة"، وبذلك فان الثكل الجديد للعمارة يجب أن يكون مبتكر اليس بهدف تو افق المسطحات و الكتل، ولكن في علاقة كل 
من المتطلبات الاجتماعية الجديدة و التكنولوجيا الحديثة و المو اد المبتكرة على أن توضع جميعا في الاعتبار بالتساوي عنديه

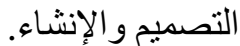

بـ ــاقة الفكر المستدام بالتصميم المعماري

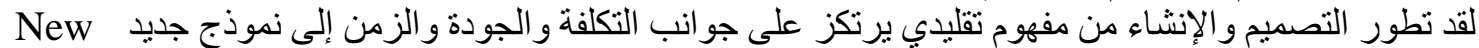

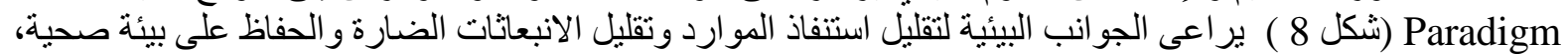

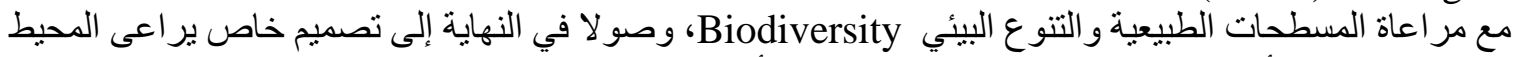

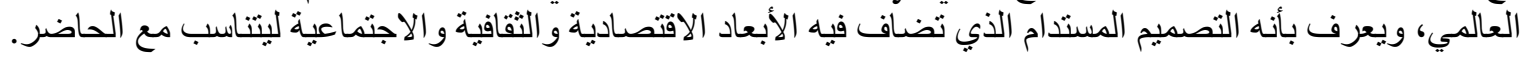

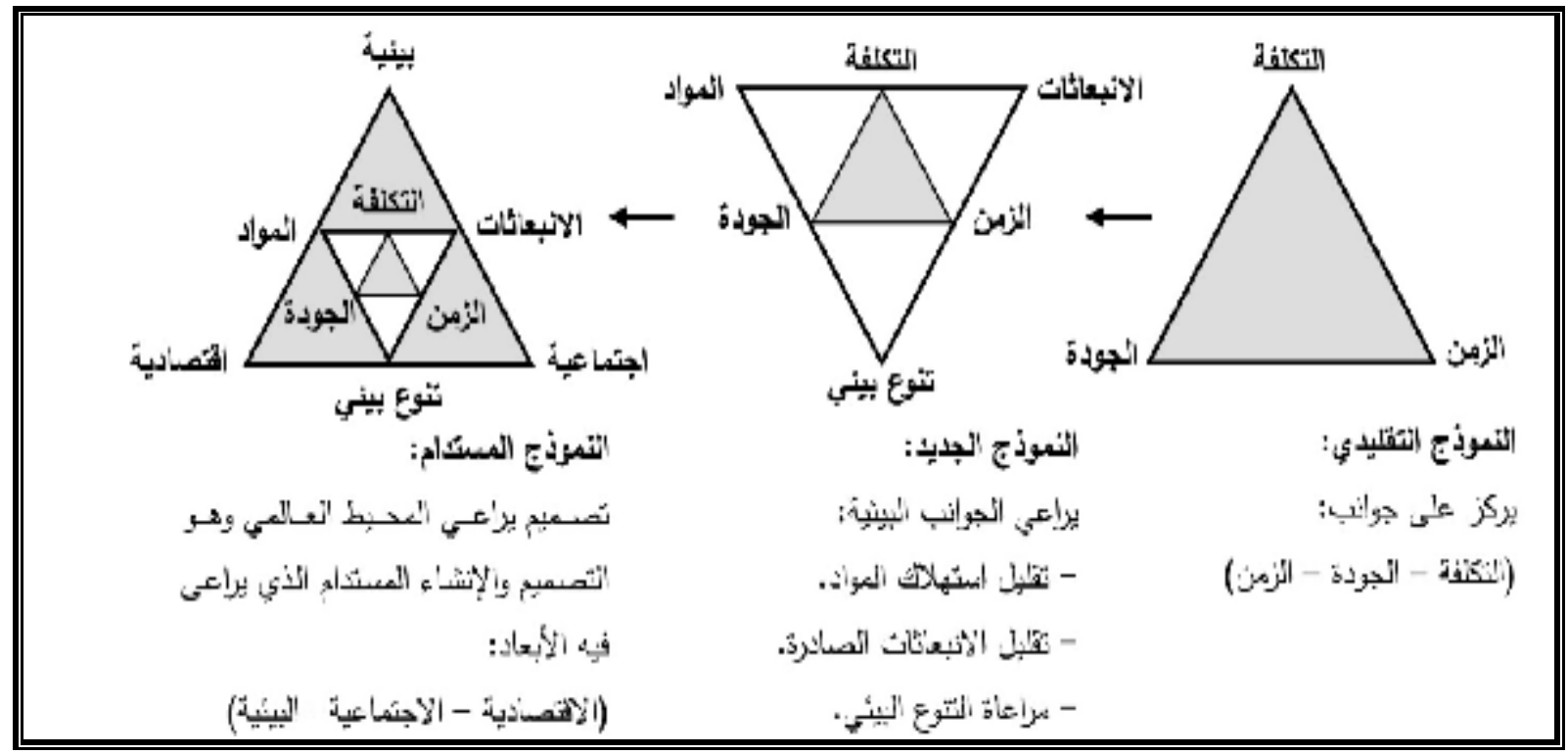

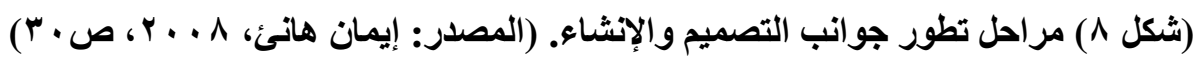

بـ 1 ـ ا الجوانب الرئيسية التي تجعل التصميم مطابق للاستدامة

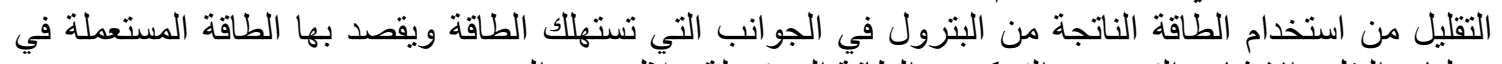

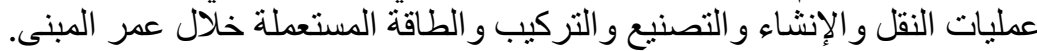

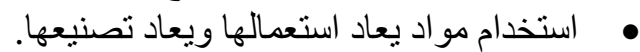

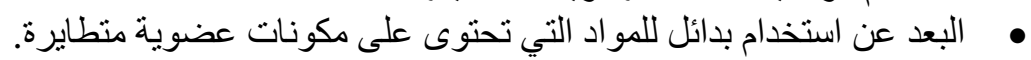

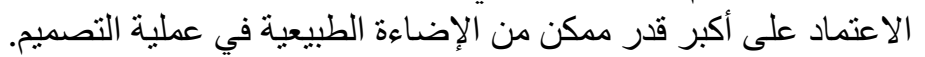

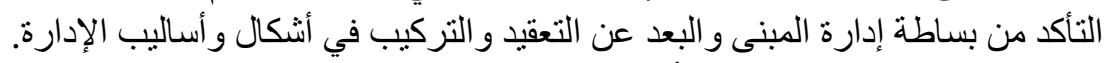

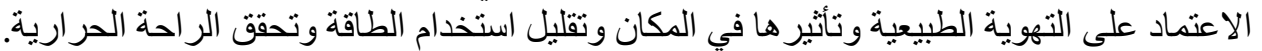

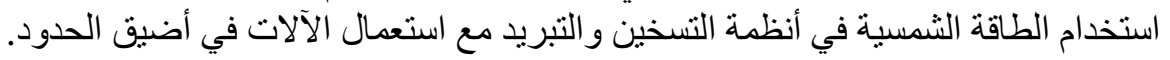

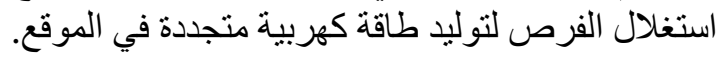

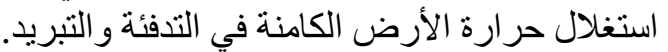

ترشيد استخدام المياه مثل جمع الأمطار ، تطهير المياه الغير نظيفة وإعادة استخدامها.

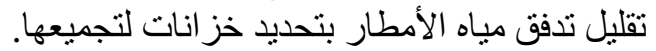
خلق بيئة خارجية تحقق الر احة في الرؤية وتعطى فو ائد بيئية مثل: التظليل في الصيف بالأشجار و التبريد بالتبخير للعناصر المائية. التأكد من أن التصميم به أعلى الأساليب القياسية المتخصصة مع أفضل تميز جمالي. 
ـ ـ معايير واستراتيجيات تصميم الرعاية الصحية المستدامة عالميا:

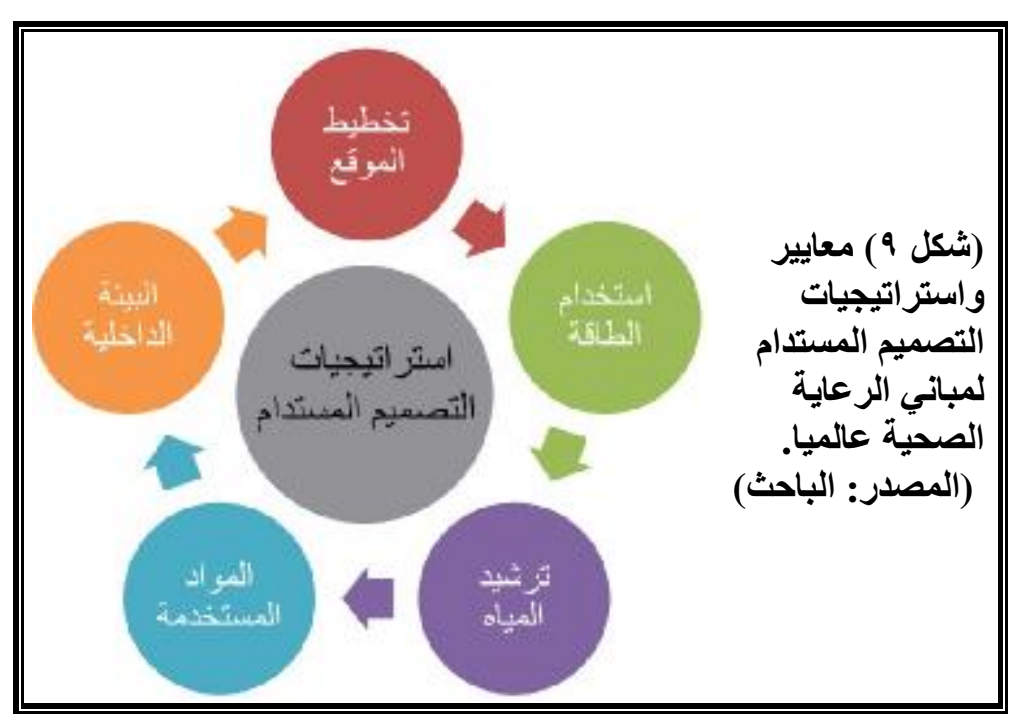

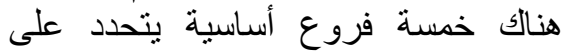
أساسها خطط و استر اتيجيات البناء المستدام

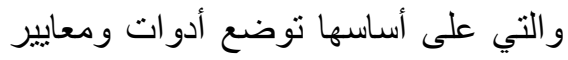

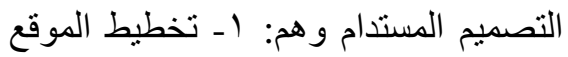

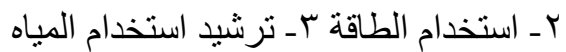
ع- المواد المستخدمة مـ ك كفاءة البيئة

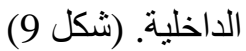

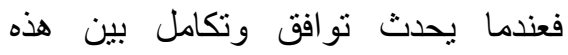

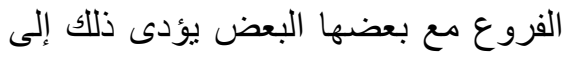

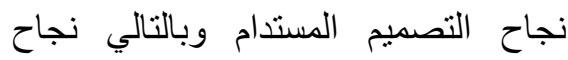
المشروع، فعلى سبيل المثال زيادة ضوء المالئاح النهار الطبيعي داخل المبنى نجد أنها بؤنثر على منطلبات الطاقة ويؤثر أيضا في الجياء سرعة شفاء المرضى، فالهدف الأساسي

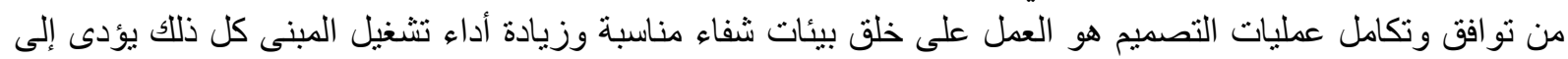
تحسين صحة المرضى وزيادة رفاهيته ويمكن تلخيص تللك المعايير في النقاط الآتية:

\begin{tabular}{|c|c|}
\hline $\begin{array}{l}\text { Site Planning and Access to } \\
\text { Nature }\end{array}$ & تخطيط الموقع والتوجيه للطبيعة \\
\hline Clean Transportation & المواصلات النظيفة \\
\hline Energy Efficiency & كفاءة الطاقة \\
\hline Water Conservation & الحفاظ على المياه \\
\hline Indoor Environmental Quality & كفاءة البيئة الداخلية \\
\hline Healthy Material Selection & اختيار المواد والخامـات الصحية \\
\hline
\end{tabular}

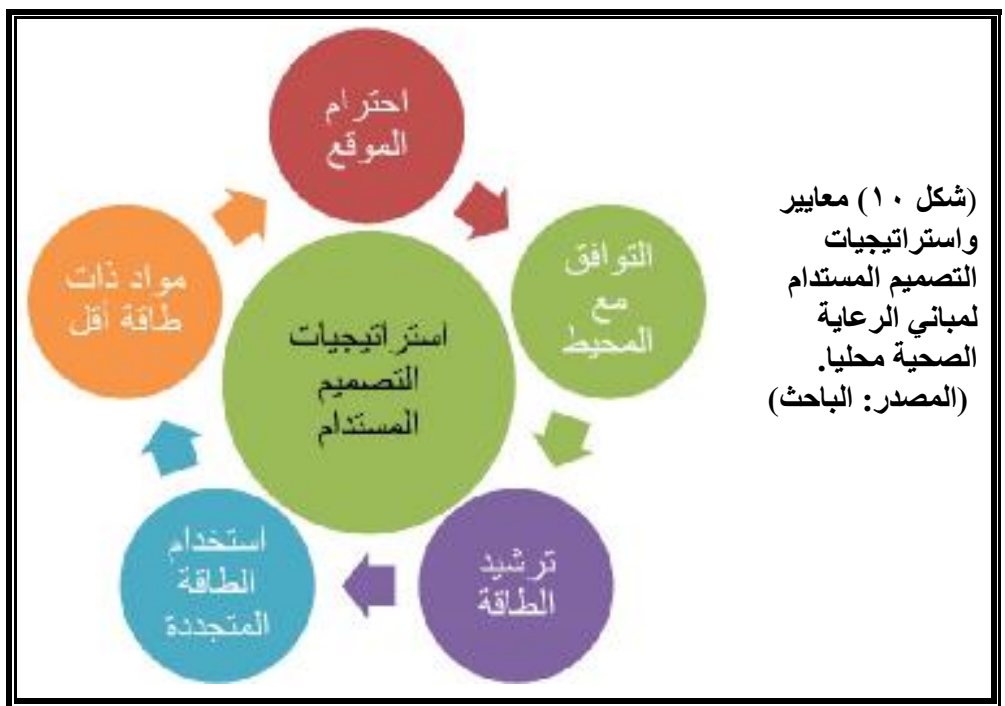

عند تصميم المستثفيات الخضراء المستدامة يجب مراعاة ما يلي :

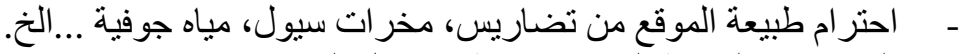

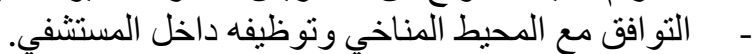
- - استخدام تقنيات ترشيد استهلاكات الطاقة. - استخدام مصادر الطاقة الجديدة والمتجددة. 
- - تقليل حجم الاستهلاك من المو اد، واستخدام مو اد ذات طاقة تنغيل منخفضة أو متوسطة. (شكل 10)

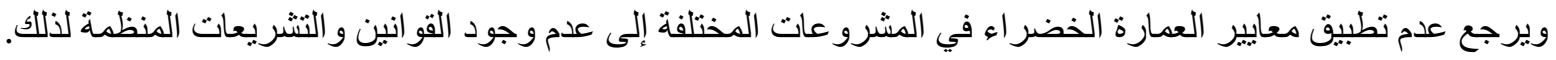

هـاستراتيجيات ومكونات التصميم المستدام لمباني الرعاية الصحية الصغية

ويستعرض البحث عدداً من المكونات الأساسية للتصميم المستدام الخاص بمباني الرعاية الصحية والمتنثل في الآتي:

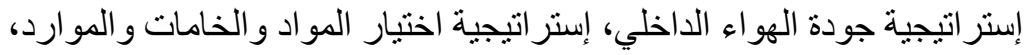

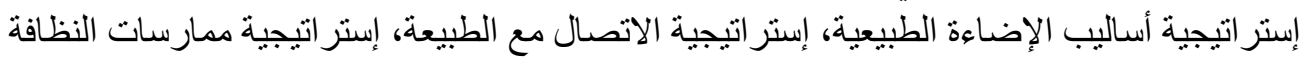

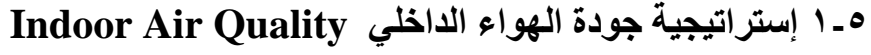

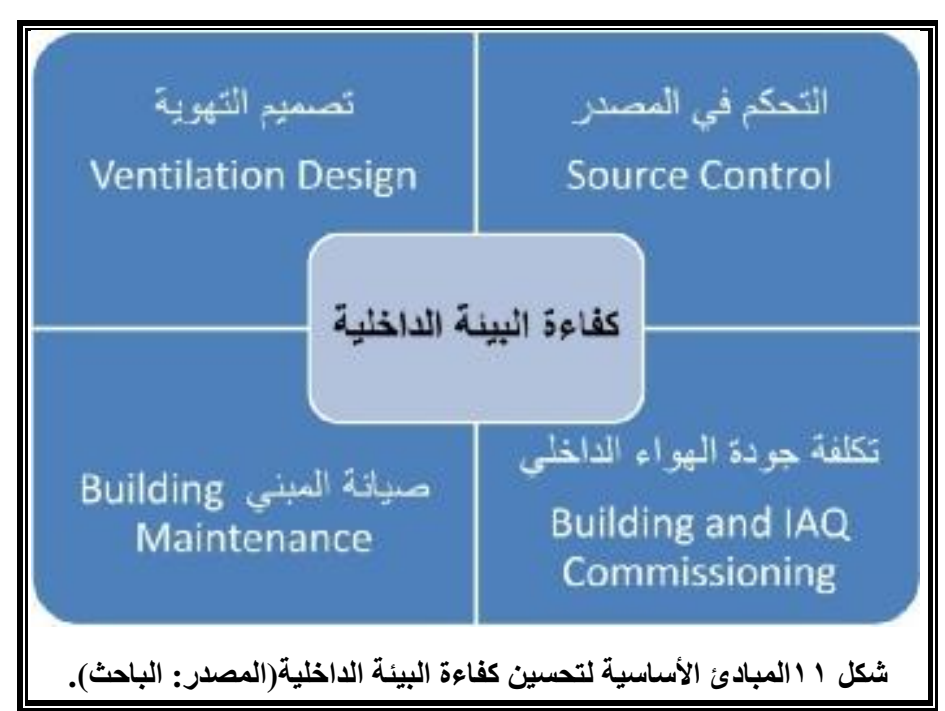

ذكرت نقارير وكالة حماية البيئة الأمريكية أن

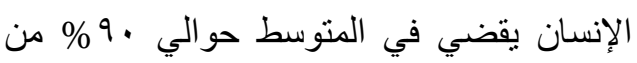
اليوم داخل البيئة المبنية، ويستنشق الإنسان أثناء

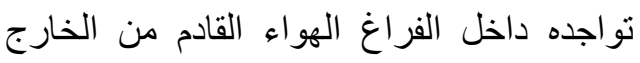

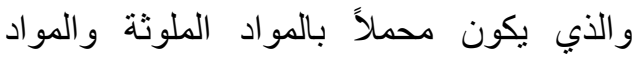
الكيميائية العديدة و الفورمالدهيد و الأوزون و التي بدور ها تتحد مع الملوثات و المو اد الكيميائية التي ولي التئي

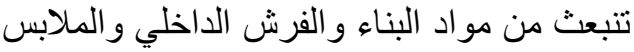
ومنتجات العناية الثخصية ومع المواد الكيميائية والملوثة التي تتبعث من الأدوات المكتبية و أدو ات النظافة.

بعد نوضيح أهم نظم التقييم الخضراء مع توضيح أهم المحددات التي يمكن التقييم علي أساسها سيتم توضيح بعضاً من

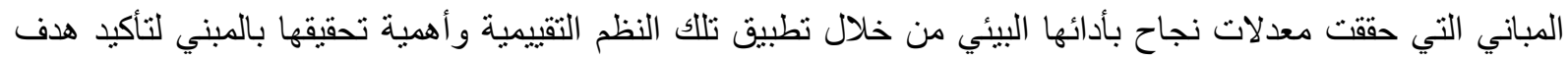
الدراسة البحثية و التي تهذف إلي محاولة إيجاد منهجية تحقق مباني رعاية صحية ذات أداء بيئي متميز يرتبط بتحقيق

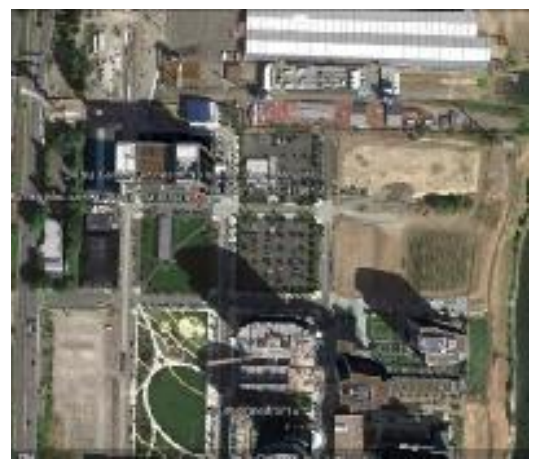

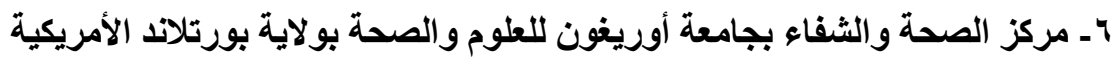

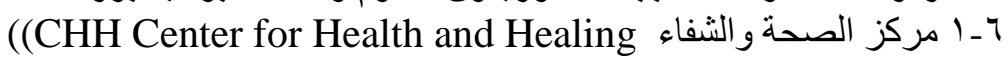

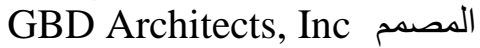

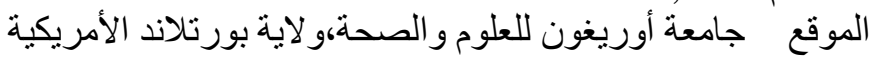

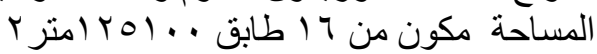

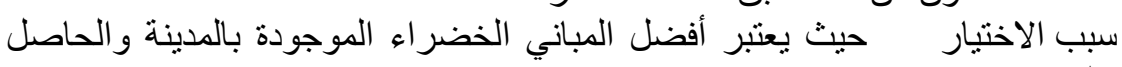
علي LED Platinum

الثهادة المعتمدة :LEED Platinum 2007 الصـادرة من مجلس المباني الخضر اء

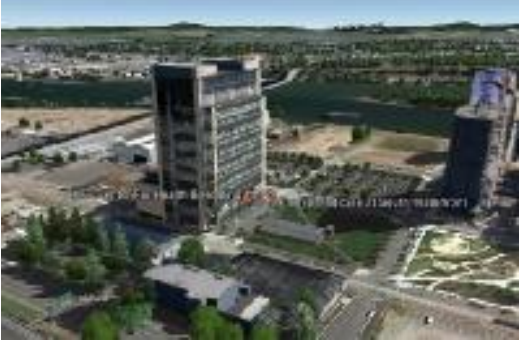

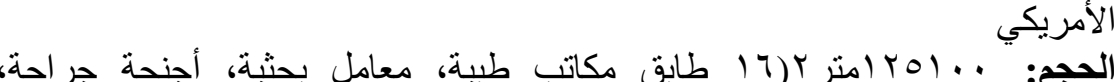

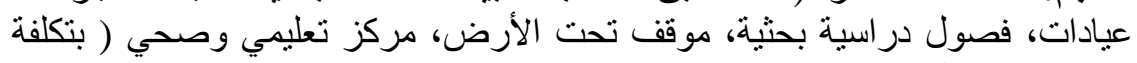

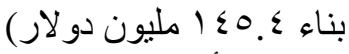

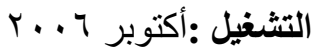

المرافق الملحقة:محطة بورتلاند العامة الكهرباء، محطة الغاز الطبيعي، محطة للطاقة. المالك : شركة المكة:فيكة

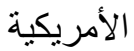

Development, Bright works Gerding Edlen LEED الأسئول التطوير، مستشارئ الإنشائي: مكتب KPFF النطوير، ماريكي 
الأعمال الكهربائية والميكانيكية والصحية و استشاري الطاقة

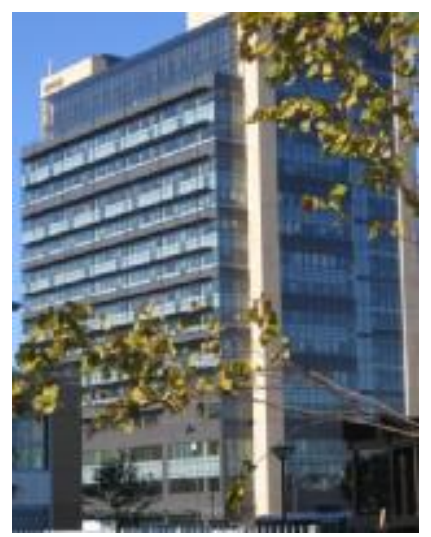
مكتب Interface Engineering الأمريكي المقاول العام شركة Hoffman Construction CB Richard Ellis إدارة المشروع العامع

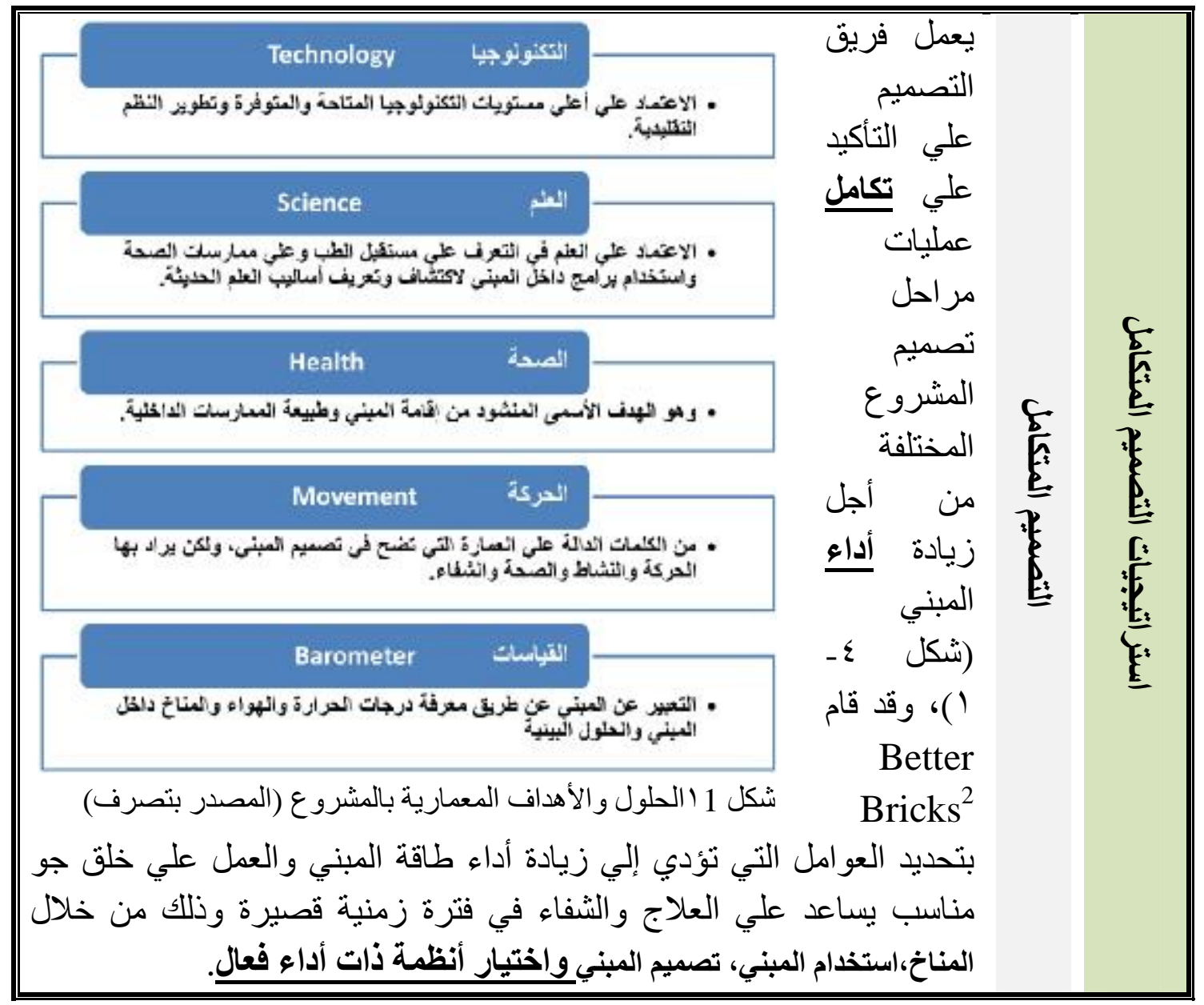


تطور التصميم البيئي المستدام لمباني الرعاية الصحية

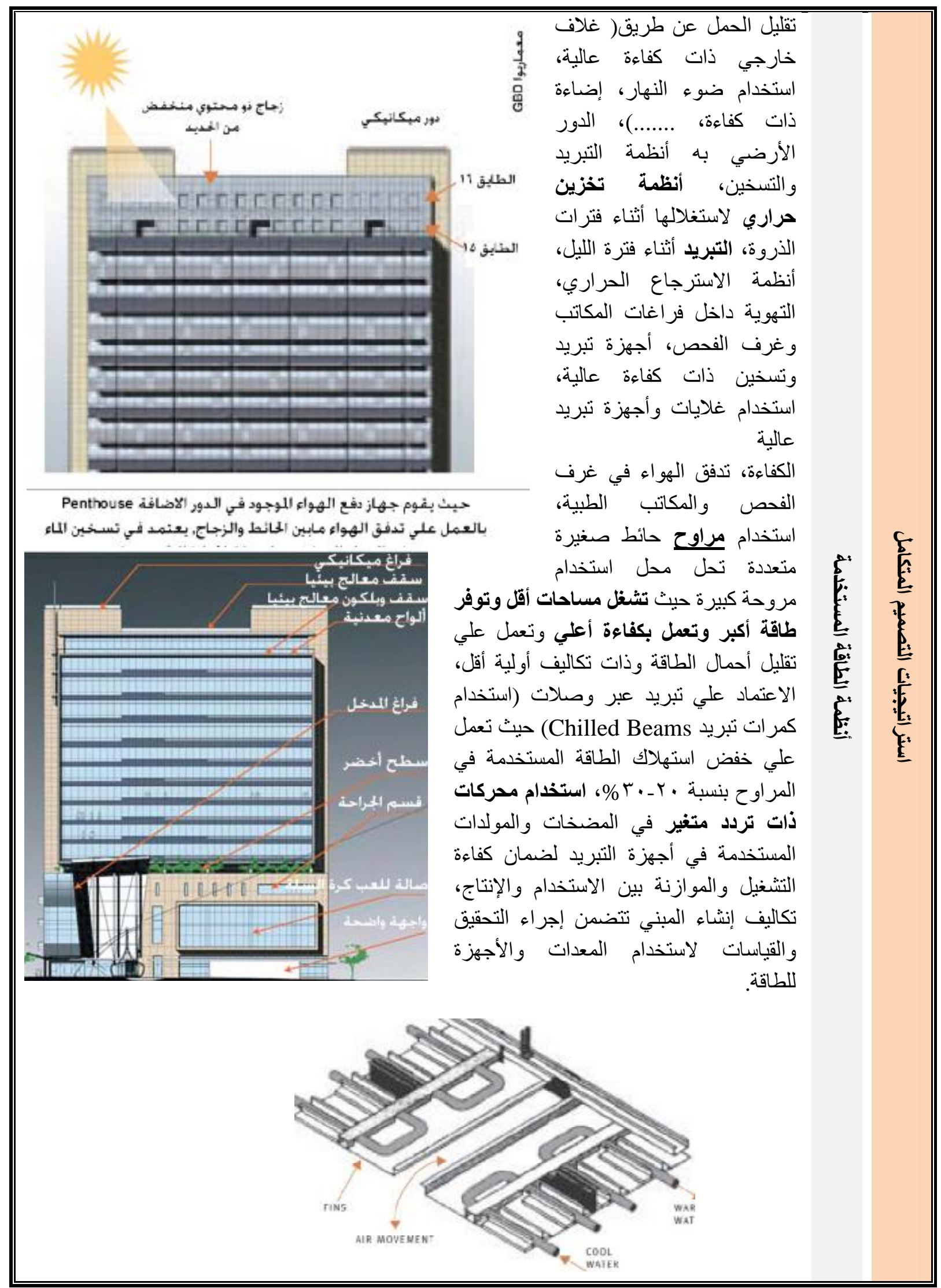




\section{- L درجات تقييم LEED الحاصل عليها المركز}

وقد ركزت معايير LEED المطبقة في مركز الصحة والثفاء علي جو انب الاستدامة في تطوير الموقع وكفاءة استهلاك

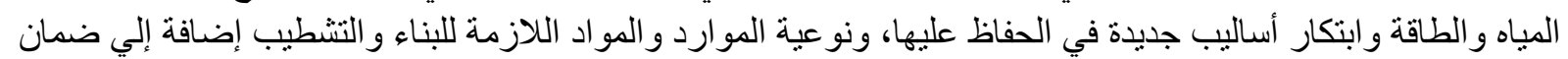
جودة البيئة الداخلية للمركز ، وقد حصل المركز علي 00 نقطة من أصل 79 نقطة أهلته للحصول علئ علي الثهادة الثادة البلاتينية

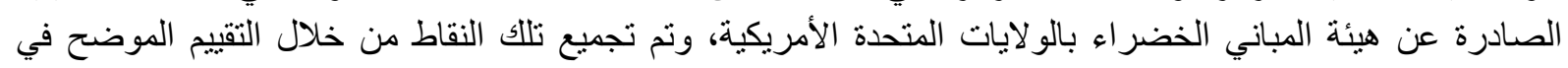

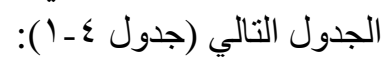

\begin{tabular}{|c|}
\hline قييمٍ الجوانب في مركز \\
\hline $1 \pi$ \\
\hline 0 \\
\hline $1 \leqslant$ \\
\hline$\wedge$ \\
\hline 1. \\
\hline 0 \\
\hline 00 \\
\hline
\end{tabular}

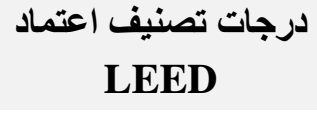

$1 \leq$

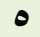

iv

$1 \%$

10

$\bullet$

79

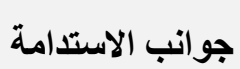

استدامة الموقع

كفاءة ترشيد استخدام المياه

كفاعة الطاقة وتوفيرها

ترشيد المواد والموارد

جودة البيئة الداخلية

التصميم والإبداع

\section{الإجمالي}

^ــ ـ أسس ومعايير تصميم مباني الرعاية الصحية في ضوء معايير الاستدامة. 1ـ 1ـ ا ـ التصميم المستدام المتكامل

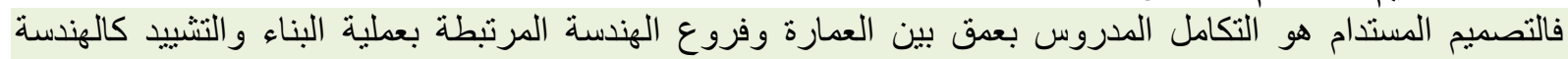

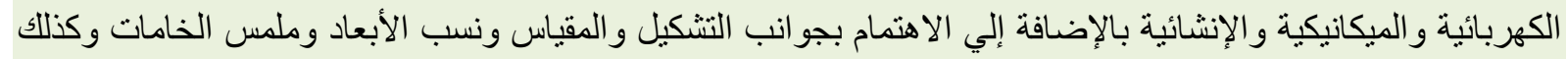

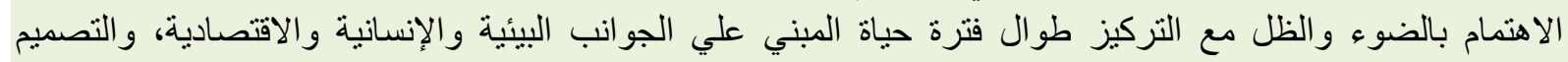

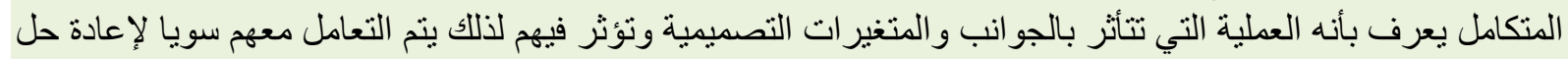

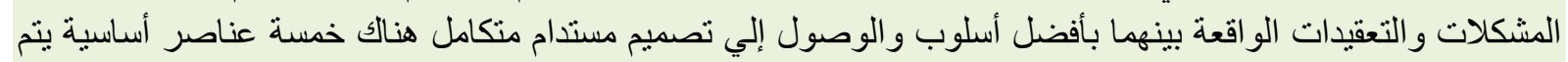
الا هتمام بها وهي كالتالي:

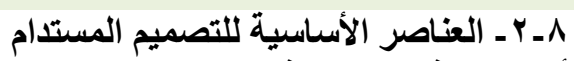

أولا: اتخاذ القرارات في المراحل المبن المبكرة

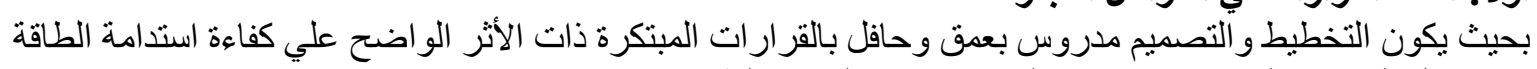
واستغلال التصميم الثمسي بالإضـافة إلي الإضـاءة و التهوية الطبيعية. 


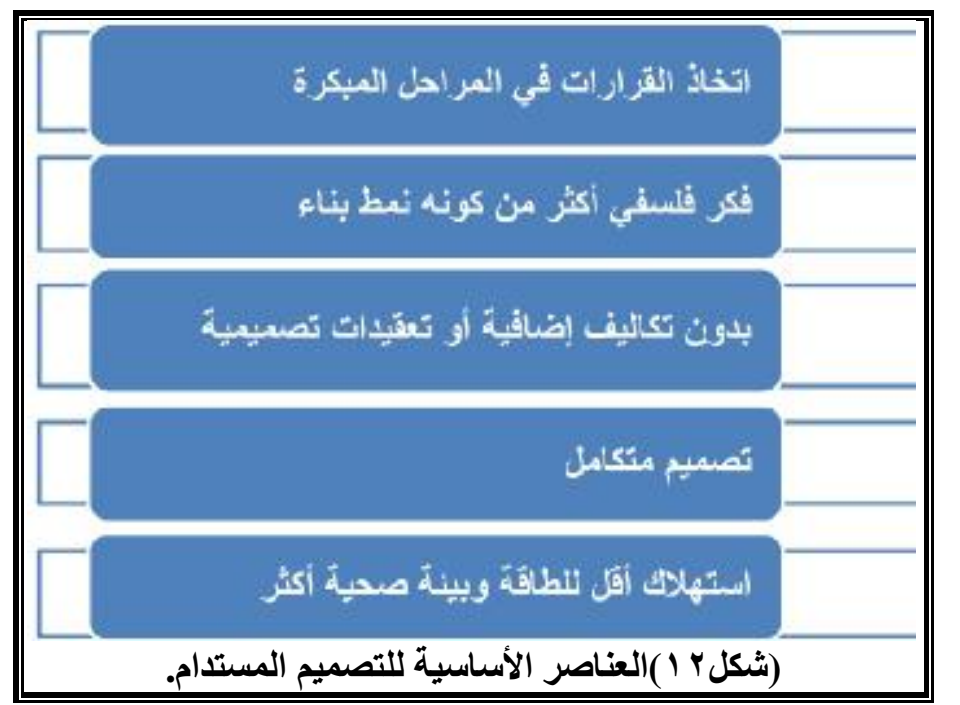

أهم ما يميز التصميم المستدام هو التكامل بين أجزاء المنظومة التهام فكل نظام ينظر إلي أهداف واستر اتيجيات النظم الأخرى

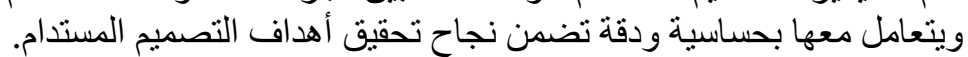

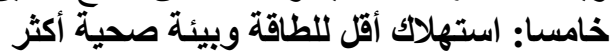

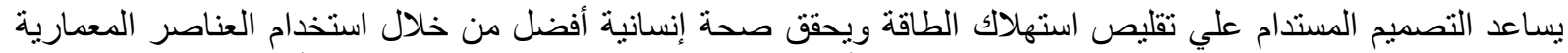
الموفرة للطاقة و الغلاف الجوي المحافظ علي الطاقة والأنظمة الكهربية و الميكانيكية و الصحية ذات أكبر الكبر كفاءة في استغلال الطاقة وتضمن مستوي صحي مرتفع للإنسان.

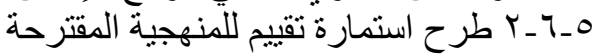

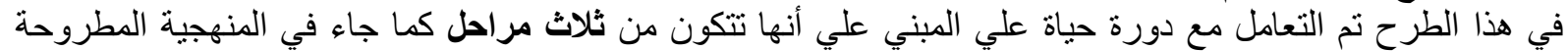

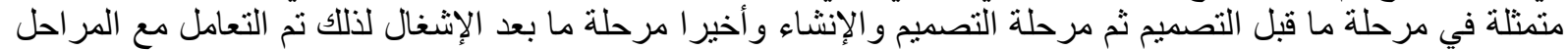

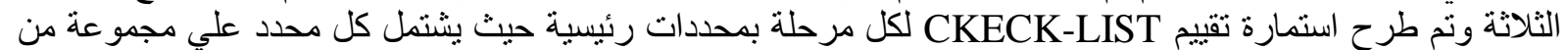

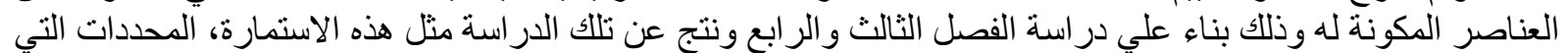

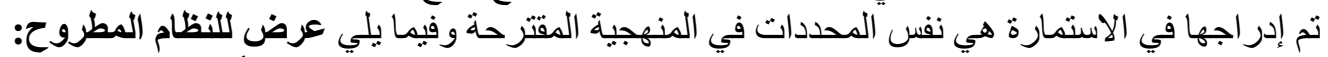

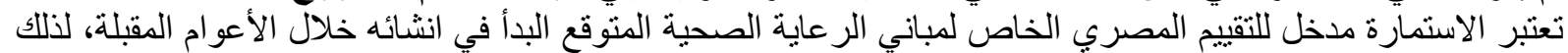

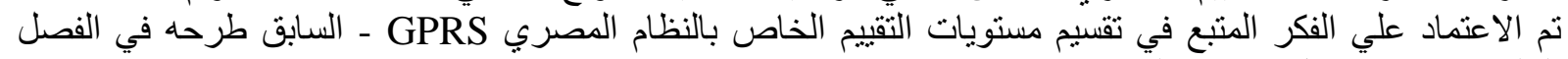

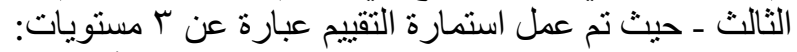

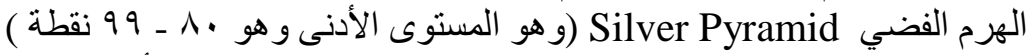

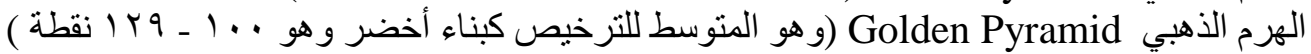

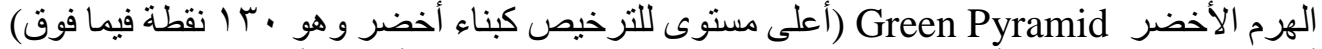

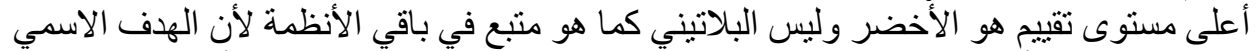

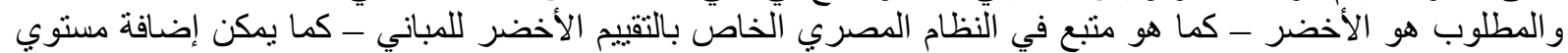

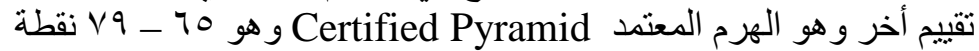

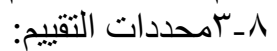

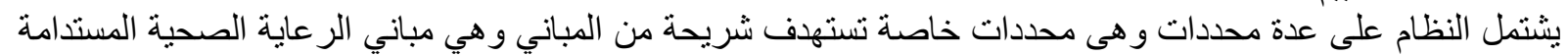

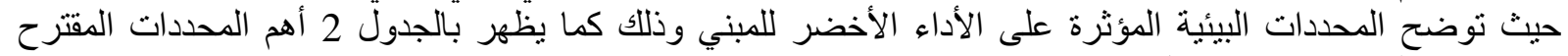
طرحها في النظاح و عدد نقاط كل محدد بعناصره النئ. 


\begin{tabular}{|c|c|c|c|c|c|}
\hline \multicolumn{6}{|c|}{ جدول ץ أهم المحددات التي تم تناولها في استمارة التقييم. ( المصدر: الباحث) } \\
\hline \multicolumn{2}{|c|}{ محددات ما بعد الإشغال } & \multicolumn{2}{|c|}{ محددات التصميم والإنشاء } & \multicolumn{2}{|c|}{ محددات ما قبل التصميم } \\
\hline 10 & والمخلفات & 7 & تصميم المبني & • & التصميم المتكامل \\
\hline 1. & خدمات الطعام & $r r$ & الطاقة & 1. & استـامـة الموقع \\
\hline 10 & التكاليف والمدخرات & $r r$ & جودة البيئة الداخلية & • & وسائل النقل البديلة \\
\hline$\wedge$ & المشتريات الأقضل بيئيا & 10 & المواد والموارد & $r$ & أولوية المنطقة \\
\hline • & المسئولية الاجتماعية & 1. & كفاءة استخدام المياه & & \\
\hline$\varepsilon$ & تطبيق فكر الاستدامة & $\bullet$ & الابتكار والإبداع في & & \\
\hline ov & المجموع & Ar & المجموع & $r r$ & المجموع \\
\hline
\end{tabular}

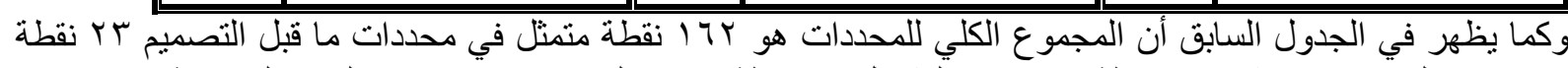

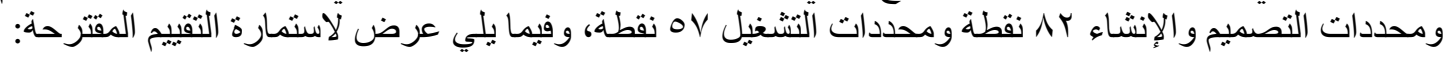

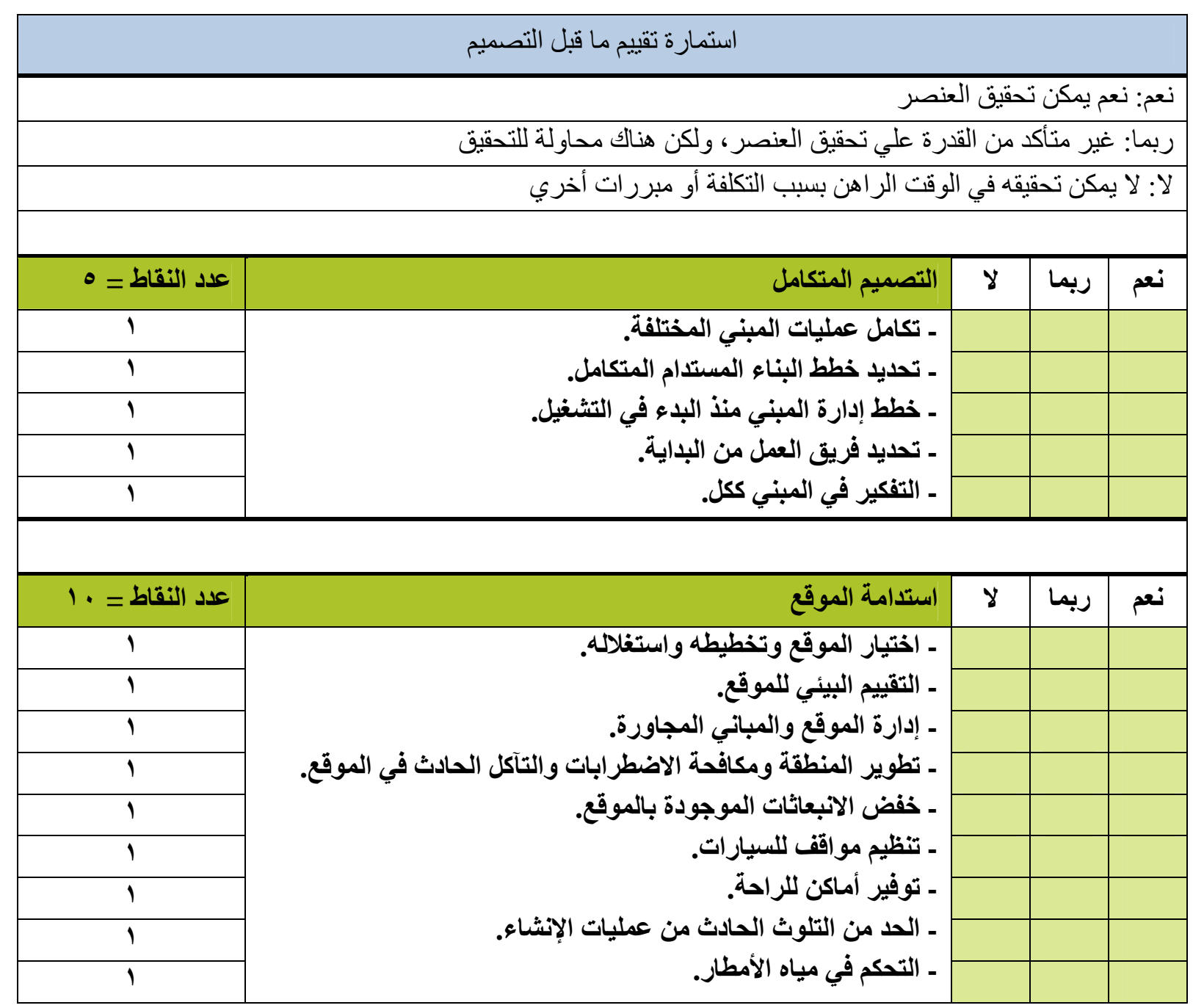


تطور التصميم البيئي المستدام لمباني الرعاية الصحية

\begin{tabular}{|c|c|c|c|c|}
\hline 1 & ـ تأثير الجزر الحرارية. & & & \\
\hline عدد النقاط = ع & وسائل النقل البديلة & $y$ & 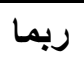 & نمعم \\
\hline 1 & ـ الاعتماد علي وسائل نقل بديلة. & & & \\
\hline 1 & ـ ذ ذات انبعاثات منخفضة. & & & \\
\hline 1 & ـ ذات استهلاك منخفض للطاقة وموفرة لها. & & & \\
\hline 1 & - وصول وسائل الذ & & & \\
\hline 1 & ـ توفير أماكن انتظار للسيارات والاراجات. & & & \\
\hline عدد النقاط = & أولوية المنطقة & $y$ & 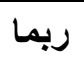 & نمعم \\
\hline 1 & ـ مدي أولوية المنطقة لإقامة المشروع. & & & \\
\hline 1 & 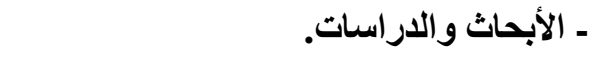 & & & \\
\hline 1 & ـ ـ نجاح المشروع في الموقع المختار. & & & \\
\hline
\end{tabular}

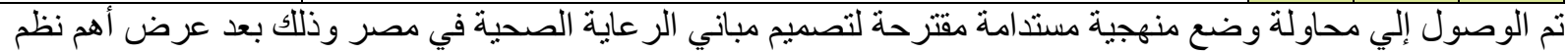

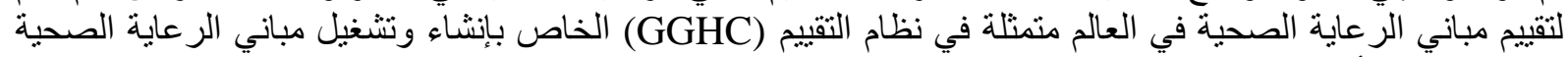

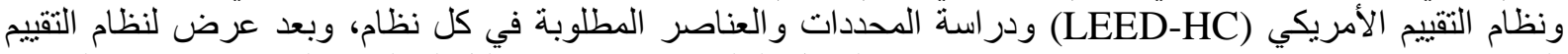

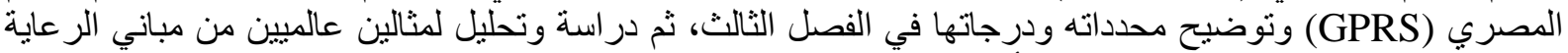

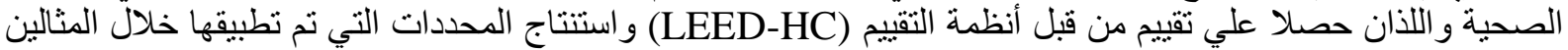

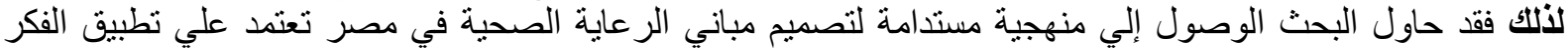

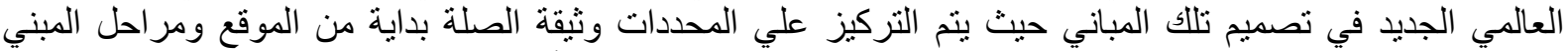

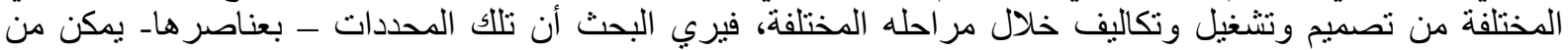
خلالها التحكم في أداء المبني ورفع مستوي الإنتاجية لدي طاقم العمل وبالتالي تحسين الحالة الصحية والنفسية لدي المرضي. تم التوصل إلي ثُلاث مراحل تساعد علي الوصول إلي منهجية رئيسية تطبق فكر الاستدامة خلال دورة حياة المبني منمثلة

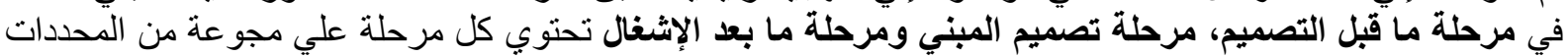

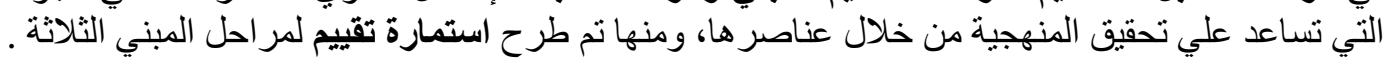

أولا: النتائج

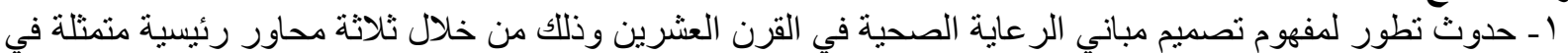

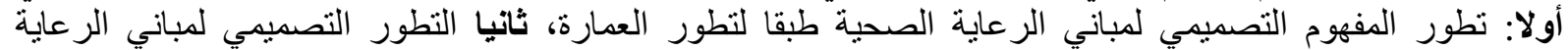

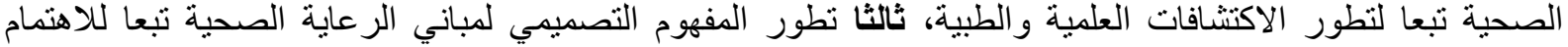

بالاحتياجات الإنسانية.

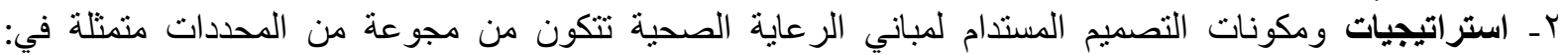

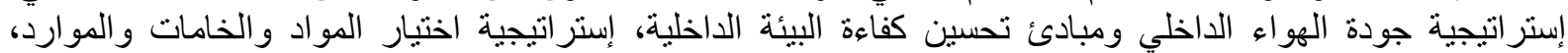

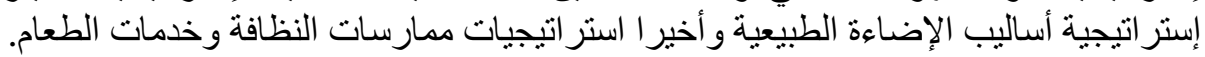

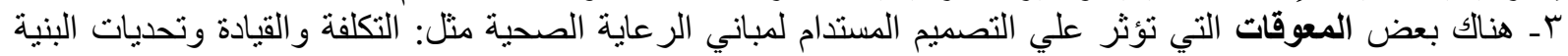
التحتبة.

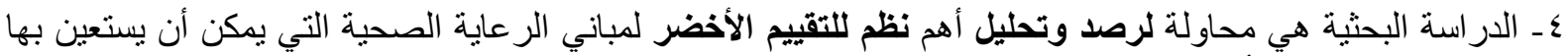

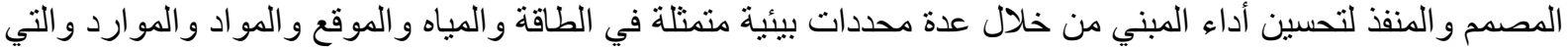
تؤدي لتحقيق بيئة مناسبة للعلاج و الثنفاء.

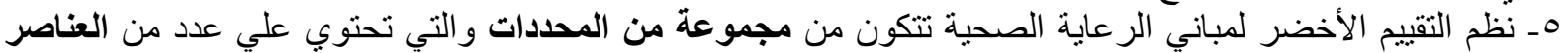

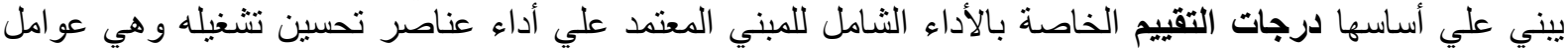

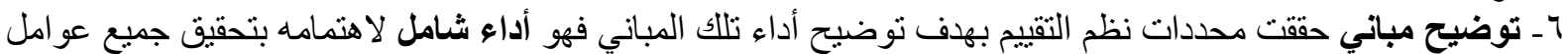
تحسين أداء المبني مقارنة بأداء المباني التقليدية و التي كانت تهتم بتميز الأداء في أحد المحددات وليس جميع المحددات التئ التي

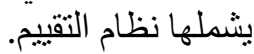




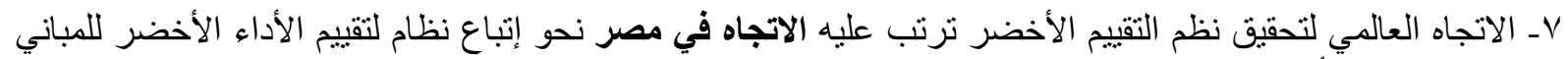

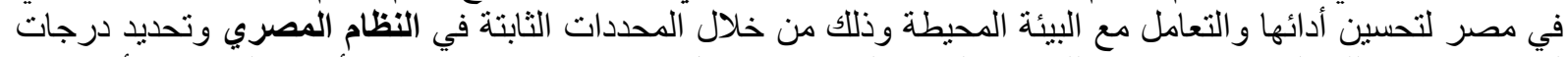

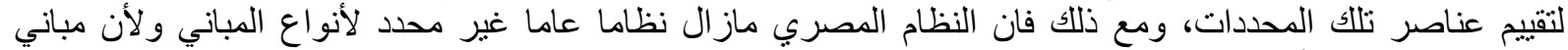

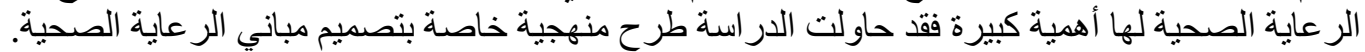

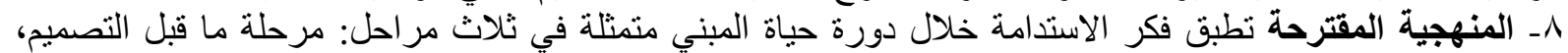

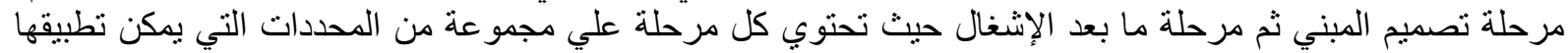
تساعد في تتفيذ محددات المنهجية المطروحة ولتطبيق تلك المنهجية و اقعيا تم عمل اسد تمارة تقييم علي المباني.

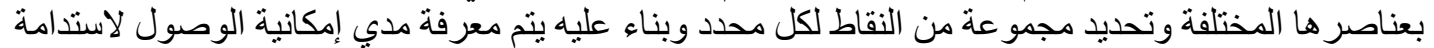

يمكن الوصول من الدراسات التوات السابقة إلي بعض التوصيات، التي من شأنها أن تساعد في تطوير التصميم المستدام لمباني

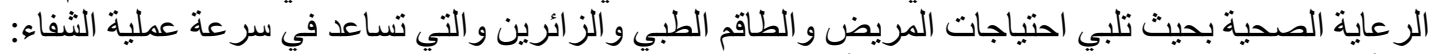

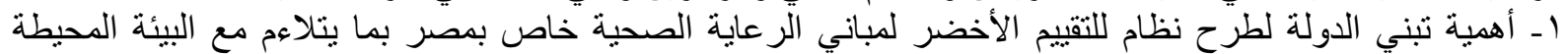

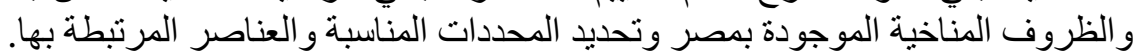

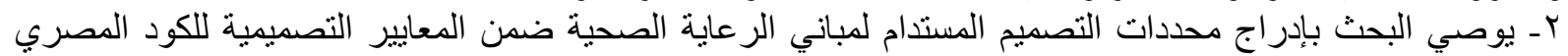

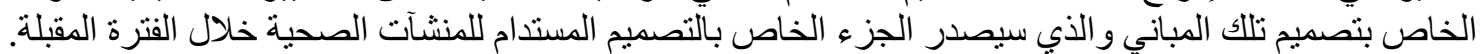

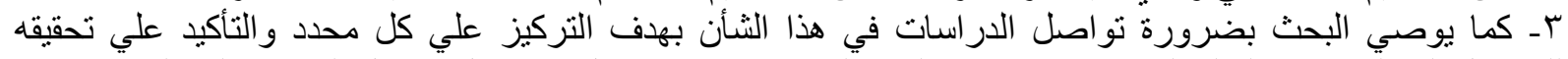

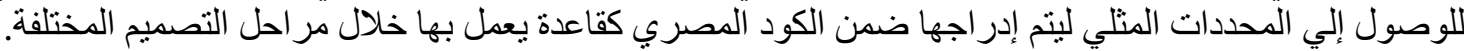

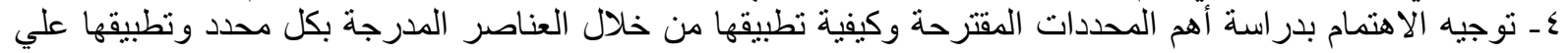
مباني الر عاية الصحية في مصر واستكمال التجارب الخاصة بهذا الهجا الهال بهدف الوصول إلي صيغة ثابتة يمكن الرجوع إليها عند البدء في مر احل التصميح.

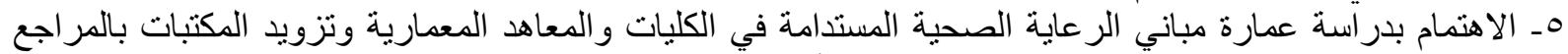

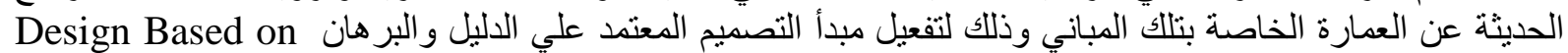

Evidence and Research

المر إجع العربية:

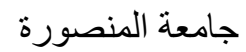

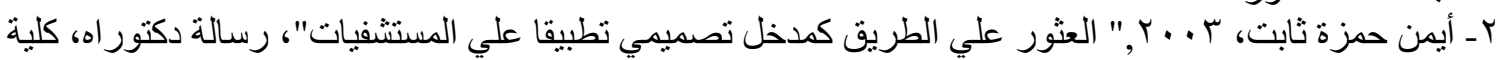

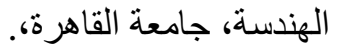

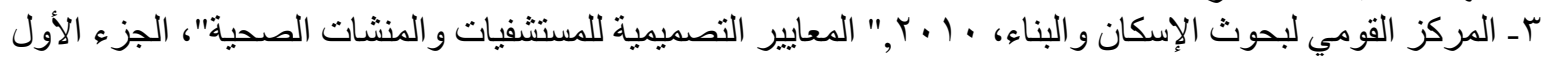

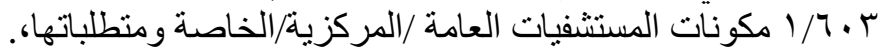

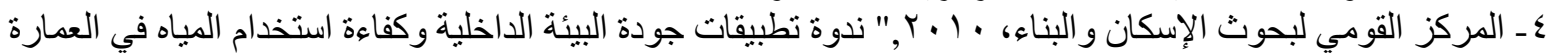

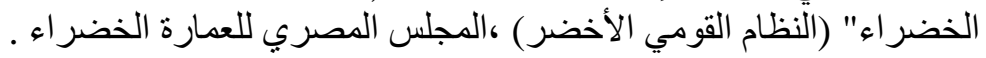

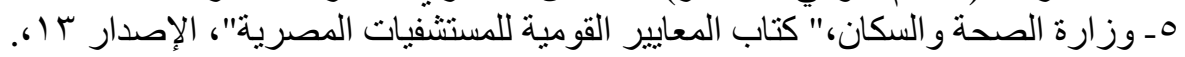

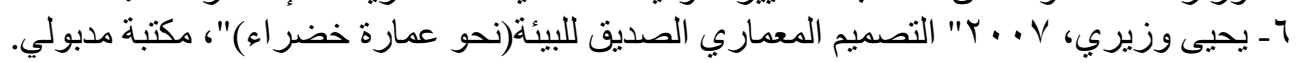

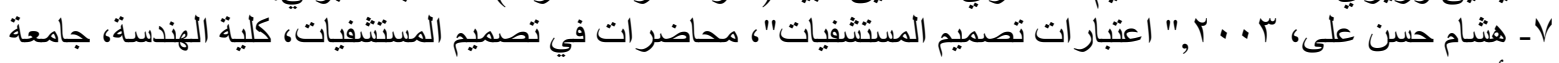
أسيوط. 1ـ المركز القومي لبحوث الإسكان و البناء، ـ 1 ـ ؟" المعايير التصميمية للمستشفيات و المنشات الصحية"، الجزء الأول

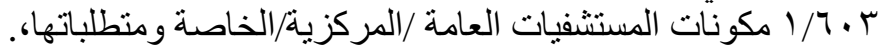

المراجع الأجنبية

1. Alexander Kuruvilla,, 2011." Medical Synergie".

2. American Society for Healthcare Engineering, 2008, ASHE ," Health Facilities Management", Green Design \& Operations Survey,.

3. Center for Chemical Dependency Recovery, 2010,"Offering a Welcoming and Healing Environment that Encourages People to Seek Treatment", California, USA.

4. Pradinuk, R. (2009). Incentivizing the daylit hospital: the green guide for health care approach. HERD: Health Environments Research \& Design Journal, 2(4), 92-112. 
5. Wittmann, M. (2010). Sustainable healthcare design. Evidence-Based Design for Healthcare Facilities, Sigma Theta Tau International, 147-186.

6. National Association of Countries, ), 2011, Washington, USA( NACo.

7. Nurture by steelcase, 2011, "Advocate Lutheran General Hospital", Chicago, Case study.

8. Randy Guillot, October 2011,"The Architecture of Change Towards a New Cancer Center Design", Chicago.

9.U.S. Green Building Council, 2011, "LEED 2009 for HEALTHCARE", for public use and display.

10. Texas Society of Architects AIA, 2011, "Texas Architect", Texas.

11. Woodner, A. (Ed.). (1999). High Performance Building Guidelines. DIANE Publishing.

12. Zborowsky, T. (2006). Step into the Patient Room of the Future. Design \& Health IV.

Future trends in healthcare design, 197-203.

13. Pilosof, N. P., \& March, M. (2005). Planning for Change: Hospital Design Theories in

Practice. Academy journal, AIA.

14. Siemens, April 2009" Technology Report", USA. 